\title{
Acetazolamide modulates intracranial pressure directly by its action on the cerebrospinal fluid secretion apparatus
}

Dagne Barbuskaite ${ }^{1}$, Eva K. Oernbo ${ }^{1}$, Jonathan H. Wardman ${ }^{1}$, Trine L. Toft-Bertelsen ${ }^{1}$, Eller Conti ${ }^{1}$, Søren N. Andreassen ${ }^{1}$, Niklas J. Gerkau ${ }^{2}$, Christine R. Rose², Nanna MacAulay ${ }^{1}$

${ }^{1}$ Department of Neuroscience, Faculty of Health and Medical Sciences, University of Copenhagen, Copenhagen, Denmark, '2Institute of Neurobiology, Heinrich Heine University Düsseldorf, Düsseldorf, Germany

\section{Corresponding Author:}

Nanna MacAulay, Department of Neuroscience, Faculty of Health and Medical Sciences, University of Copenhagen, Blegdamsvej 3, Copenhagen, DK-2200, Denmark. Phone: +4535327566, Email: macaulay@sund.ku.dk

Keywords: $\mathrm{CSF}$ secretion, ICP, hydrocephalus, $\mathrm{IHH}$, choroid plexus, $\mathrm{HCO}_{3}{ }^{-}$transporters

Running title: Acetazolamide lowers ICP via its reduction of CSF secretion 


\section{Abstract}

Elevated intracranial pressure (ICP) is observed in many neurological pathologies, e.g. hydrocephalus and stroke. This condition is routinely relieved with neurosurgical approaches, since effective and targeted pharmacological tools are still lacking. The carbonic anhydrase inhibitor, acetazolamide (AZE), may be employed to treat elevated ICP. However, its effectiveness is questioned, its location of action unresolved, and its tolerability low. Here, we employed in vivo and ex vivo approaches to reveal the efficacy and mode of action of AZE in the rat brain. The drug effectively reduced the ICP, irrespective of the mode of drug administration and level of anaesthesia. The effect occurred via a direct action on the choroid plexus and an associated decrease in cerebrospinal fluid secretion, and not indirectly via the systemic action of AZE on renal and vascular processes. Upon a single administration, the reduced ICP endured for approximately $10 \mathrm{~h}$ post-AZE delivery with no long-term changes of brain water content or choroidal transporter expression. However, a persistent reduction of ICP was secured with repeated AZE administrations throughout the day. Future specific targeting of choroidal carbonic anhydrases may limit the systemic side effects, and therefore enhance the treatment tolerability and effectiveness in select patient groups experiencing elevated ICP. 
bioRxiv preprint doi: https//doi.org/10.1101/2022.01.11.475854 this version posted January 12,2022 . The copyright holder for this preprint (which was not certified by peer review) is the author/funder, who has granted bioRxiv a license to display the preprint in perpetuity. It is made available under aCC-BY-NC-ND 4.0 International license.

\section{Introduction}

Elevated intracranial pressure (ICP) is observed in various brain pathologies. It causes spatial compression of the brain tissue and reduced cerebral perfusion, and if left untreated, leads to cerebral ischaemia and may be fatal (1). Treatment of elevated ICP relies heavily on surgical interventions, most commonly ventriculoperitoneal shunting in hydrocephalic patients, and craniectomy in severe cases of brain edema (2). Only a few pharmacological options are available for relief of elevated ICP, the most widely used being Diamox $^{\circledR}$, with the active ingredient acetazolamide (AZE) (3). AZE is an inhibitor of the carbonic anhydrases, the 15 isoforms of which are widely expressed in different cell types and tissues throughout the mammalian body (4). These enzymes catalyse the reversible conversion of $\mathrm{CO}_{2}$ to $\mathrm{H}_{2} \mathrm{CO}_{3}$, which is followed by its dissociation to hydrogen ion $\left(\mathrm{H}^{+}\right)$and bicarbonate $\left(\mathrm{HCO}_{3}{ }^{-}\right)$. AZE was launched in the early 1950 s as a diuretic agent (5), and later employed for treatment of elevated ICP (6). However, although some clinical studies revealed AZE-mediated ICP decrease (7), others demonstrated modest, if any, effect of AZE treatment $(8,9)$. Due to its wide expression, AZE treatment associates with a range of systemic side effects, e.g. paraesthesia, dysgeusia, polyuria and fatigue (10). The uncertainty regarding AZE efficiency, combined with poor patient compliance, has raised questions regarding its usability in the clinic (11). Notwithstanding, due to lack of alternatives, AZE remains a first-line treatment for certain ICP pathologies, e.g. idiopathic intracranial hypertension (12), irrespective of the unresolved mode of action by which the drug may confer relief of elevated ICP. Studies on experimental animals have remained equally inconclusive as AZE administration did $(13,14)$ or did not $(15)$ reduce the ICP.

In contrast to its unclear effects on ICP, there is solid preclinical data supporting AZE's efficacy in lowering cerebrospinal fluid (CSF) secretion in humans $(16,17)$ as well as in different experimental animal models, i.e. sheep (18), dogs (19), rabbits (20-24), cats (25-28) and rats (29-31) (for review, see (32)). The majority of the CSF is secreted by the choroid plexus (33), which is an epithelial monolayer with a polarised expression of various ion transporters and channels $(34,35)$. Amongst these choroidal membrane transport mechanisms are several $\mathrm{HCO}_{3}{ }^{-}$transporters, i.e. the sodium- 
bioRxiv preprint doi: https://doi.org/10.1101/2022.01.11.475854; this version posted January 12, 2022. The copyright holder for this preprint (which was not certified by peer review) is the author/funder, who has granted bioRxiv a license to display the preprint in perpetuity. It is made available under aCC-BY-NC-ND 4.0 International license.

driven chloride bicarbonate exchanger (NBCn2/NCBE) (36) and the anion exchanger 2 (AE2) (37) residing in the basolateral membrane, and the sodium bicarbonate cotransporter 2 (NBCe2) expressed in the luminal membrane $(38,39)$, all of which may be implicated in CSF secretion $(40,41)$. The activity of these transporters is determined by the availability of their substrate $\left(\mathrm{HCO}_{3}{ }^{-}\right)$. Inhibition of the choroidal carbonic anhydrases (42-46), and the ensuing reduction in $\left[\mathrm{HCO}_{3}{ }^{-}\right]_{\mathrm{i}}$ in the choroid plexus tissue, therefore directly affects the transport rate and the associated CSF secretion. However, the rate of CSF secretion could also be modulated as a secondary effect of carbonic anhydrase inhibition elsewhere in the body. An example of such AZE-mediated modulation of physiological parameters occurs in the kidney, where carbonic anhydrase-mediated $\mathrm{HCO}_{3}{ }^{-}$conversion is required for the reabsorption of $\mathrm{HCO}_{3}^{-}$(47). Inhibition of renal carbonic anhydrase might thus indirectly reduce the activity of the $\mathrm{HCO}_{3}{ }^{-}$transporters in choroid plexus by simply reducing blood $\mathrm{HCO}_{3}{ }^{-}$, thereby limiting access to their transported substrate. In addition, the AZE-mediated reduction in renal $\mathrm{HCO}_{3}{ }^{-}$ reabsorption causes diuresis that, in turn, reduces the mean arterial blood pressure (MAP) $(48,49)$. Alteration in MAP is proposed to indirectly affect CSF secretion (50), and could thus lower the ICP in this manner. Furthermore, carbonic anhydrases in erythrocytes and the surrounding capillary endothelium supports efficient $\mathrm{CO}_{2}$ exchange between the tissue-blood-alveoli (51). Inhibition of such vascular carbonic anhydrases causes systemic elevation of the partial carbon dioxide pressure $\left(\mathrm{pCO}_{2}\right)$ $(52,53)$ and ensuing hyperventilation, which may indirectly decrease the ICP $(54)$. Uncontrolled breathing of anaesthetized animals that are not mechanically ventilated during the experimental procedure may thereby represent a confounding element to the former preclinical studies evaluating AZE-mediated effects on CSF secretion or ICP (55).

AZE is thus potentially a clinically useful pharmacological agent employed to reduce ICP in neurological conditions. However, it is unclear, if the well-established AZE-mediated reduction in CSF secretion does in fact lead to an associated reduction in ICP. Another key question is whether the reduced CSF secretion arises from AZE's direct effect on choroidal carbonic anhydrases or occurs secondarily to AZE's modulatory effect on other physiological processes such as blood pressure, kidney function, 
bioRxiv preprint doi: https://doi.org/10.1101/2022 01.11.475854 this version posted January 12, 2022. The copyright holder for this preprint (which was not certified by peer review) is the author/funder, who has granted bioRxiv a license to display the preprint in perpetuity. It is made available under aCC-BY-NC-ND 4.0 International license.

and/or blood gas content. Here, we demonstrate by complementary ex vivo and in vivo experimental approaches, conducted on both anesthetized and awake rats, that AZE lowers the ICP in healthy rats by its direct action on the choroidal carbonic anhydrases and subsequent reduction in CSF secretion. This new insight may guide future pharmacological treatment of elevated ICP targeted specifically to the choroid plexus. 


\section{Methods}

\section{Animals}

Experiments were conducted in 9-10 week old male Sprague Dawley rats, housed in a temperaturecontrolled room with a $12 \mathrm{~h}: 12 \mathrm{~h}$ light-dark cycle (6am to $6 \mathrm{pm}$ ), and with free access to a standard rodent pellet diet and tap water. Animals were randomly allocated to each treatment group, and all experimental work was performed and reported in compliance with the ARRIVE guidelines (56).

\section{AZE and control solution formulation}

For i.v. administration, AZE (A6011, Sigma-Aldrich) was dissolved in $5 \mathrm{~N} \mathrm{NaOH}$ to a $700 \mathrm{mg} \mathrm{ml}^{-1}$ stock solution, which was diluted in $0.9 \% \mathrm{NaCl}$ to a working concentration of $20 \mathrm{mg} \mathrm{ml}^{-1}, \mathrm{pH} 8.4$. The control solution (vehicle) was an equiosmolar $1.4 \% \mathrm{NaCl}$ solution, $\mathrm{pH} 8.4$. The solutions ( $5 \mathrm{ml} \mathrm{kg}^{-1}$ animal) were injected into either the femoral or the tail vein, resulting in a dose of $100 \mathrm{mg} \mathrm{AZE} \mathrm{kg}^{-1}$ animal. For the intracerebroventricular (i.c.v.) delivery, AZE was dissolved in DMSO (1-2.5 M), and further diluted in either $\mathrm{HCO}_{3}{ }^{-}$-containing artificial CSF (aCSF; (in mM) $120 \mathrm{NaCl}, 2.5 \mathrm{KCl}, 2.5 \mathrm{CaCl}_{2}, 1.3 \mathrm{MgSO}_{4}, 1 \mathrm{NaH}_{2} \mathrm{PO}_{4}$, 10 glucose, $25 \mathrm{NaHCO}_{3}$, pH adjusted with $95 \% \mathrm{O}_{2} / 5 \% \mathrm{CO}_{2}$ ) or in HEPES-buffered artificial CSF (HEPESaCSF; (in mM) $120 \mathrm{NaCl}, 2.5 \mathrm{KCl}, 2.5 \mathrm{CaCl}_{2}, 1.3 \mathrm{MgSO}_{4}, 1 \mathrm{NaH}_{2} \mathrm{PO}_{4}, 10$ glucose, $17 \mathrm{Na}$-HEPES (4-(2hydroxyethyl)-1-piperazineethanesulfonic acid), $\mathrm{pH}$ 7.4), when the solution could not be equilibrated with $95 \% \mathrm{O}_{2} / 5 \% \mathrm{CO}_{2}$. Depending on the experimental paradigm, the final working solutions were formulated to expose the choroid plexus tissue with a 200-500 $\mu$ M AZE concentration, which should block carbonic anhydrases by $99.99 \%$ (57). Vehicle consisted of matching DMSO concentration (maximum $0.1 \%$ ) with addition of mannitol when required to obtain equiosmolar solutions. For chronic oral (p.o.) administration, a suspension of AZE (in $0.9 \% \mathrm{NaCl}, 50 \mathrm{mg} \mathrm{ml}^{-1}$ ) was delivered to the experimental rats in quantities $(0.9-1.0 \mathrm{ml})$ to result in $100 \mathrm{mg} \mathrm{kg}^{-1}$ animal AZE once daily for 7 days (at $10 \mathrm{am}$ ) or 3 times per day (at $7 \mathrm{am}, 2 \mathrm{pm}$ and $9 \mathrm{pm}$ ) for 5 days by oral gavage. Control animals received saline via oral gavage.

\section{Anesthesia and physiological parameter monitoring}


All non-survival surgeries were performed in rats anaesthetized with xylazine and ketamine (ScanVet, $10 \mathrm{mg} \mathrm{kg}^{-1}$ animal xylazine, $5 \mathrm{~min}$ later $100 \mathrm{mg} \mathrm{kg}^{-1}$ animal ketamine, half dose of ketamine was redosed every $10-40 \mathrm{~min}$ upon detection of foot reflex). Body temperature was maintained at $37^{\circ} \mathrm{C}$ by a homeothermic monitoring system (Harvard Apparatus). In experiments lasting for more than 30min, rats were tracheostomized and mechanically ventilated with the VentElite system (Harvard

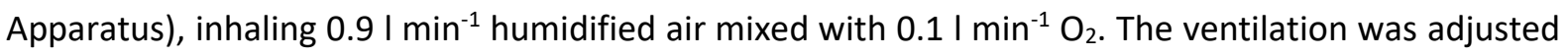
according to exhaled end tidal $\mathrm{CO}_{2}\left(\right.$ etCO $\mathrm{C}_{2}$ ), measured with a capnograph (Type 340, Harvard Apparatus), to result in $5.0 \pm 0.5 \mathrm{kPa}$ blood $\mathrm{pCO}_{2}$ before administration of control or drug solutions. In the hyperventilation experiments, the ventilation used during the baseline period was increased by $50 \%$ (both respiratory rate and the tidal volume), and then maintained at these levels throughout the $2 \mathrm{~h}$ experiment. The MAP was monitored through a heparinized saline-filled (15 IU heparin $\mathrm{ml}^{-1}$ in $0.9 \%$ $\mathrm{NaCl}$ ) catheter inserted into the femoral artery, connected to a pressure transducer APT300, and transducer amplifier module TAM-A (Hugo Sachs Elektronik). The blood pressure signal was recorded at a $1 \mathrm{kHz}$ sampling rate using BDAS Basic Data Acquisition Software (Hugo Sachs Elektronik). This catheter also served for blood sample collection required for blood gas determination with an ABL80 (Radiometer). All survival surgeries were performed under aseptic conditions on rats anesthetized with isoflurane (Attane vet, $1000 \mathrm{mg} \mathrm{g}^{-1}$ isoflurane, ScanVet), using $5 \%$ isoflurane (mixed with $1.8 \mathrm{I}$ $\mathrm{min}^{-1}$ air $/ 0.2\left(\mathrm{~min}^{-1} \mathrm{O}_{2}\right)$ in the anesthesia induction chamber, and 1-2.5\% isoflurane to maintain anesthesia through a face mask throughout the surgery. The body temperature was maintained at $37^{\circ} \mathrm{C}$ by a homeothermic monitoring system (Harvard Apparatus).

\section{ICP recordings in anesthetized rats}

Anesthetized and ventilated rats, placed in a stereotactic frame, had the skull exposed, and a $3.6 \mathrm{~mm}$ diameter cranial window drilled with care not to damage the dura. The epidural probe (PlasticsOne, C313G) was secured with dental resin cement (Panavia SA Cement, Kuraray Noritake Dental Inc.) and the ICP cannula was filled with HEPES-aCSF before connection to a pressure transducer APT300 and transducer amplifier module TAM-A (Hugo Sachs Elektronik). To ensure the presence of a continuous 
fluid column between the dura and the epidural probe, approximately $5 \mu \mathrm{l} \mathrm{HEPES-aCSF}$ was injected through the epidural probe. The ICP signal was recorded at a $1 \mathrm{kHz}$ sampling rate using BDAS Basic Data Acquisition Software (Hugo Sachs Elektronik). Jugular compression was applied to confirm proper ICP recording. In the ICP recording during i.c.v. delivery of test solutions, a $0.5 \mathrm{~mm}$ burr hole was drilled contralateral to the ICP probe ( $1.3 \mathrm{~mm}$ posterior, $1.8 \mathrm{~mm}$ lateral to bregma), and a $4 \mathrm{~mm}$ brain infusion cannula (Brain infusion kit2, Alzet) placed into the lateral ventricle. Upon stabilization of the ICP signal, $37^{\circ} \mathrm{C}$ aCSF $+0.9 \%$ DMSO was infused $\left(0.5 \mu \mathrm{min}^{-1}\right)$ with a peristaltic pump for $25 \mathrm{~min}$ prior to solution shift to either control solution ( $\mathrm{ACSF}+$ mannitol $+0.9 \%$ DMSO) or AZE (aCSF + $18 \mathrm{mM}$ AZE in $0.9 \%$ DMSO; expected ventricular concentration of $500 \mu \mathrm{M}$, equivalent to an accumulated $0.24 \mathrm{mg}$ animal ${ }^{-}$ ${ }^{1}$ over the experimental timeline) for $120 \mathrm{~min}$. In the ICP experiments with i.v. delivery of test solutions, these were injected into the femoral vein through a heparinized saline-filled (15 $\mathrm{U}$ heparin $\mathrm{ml}^{-1}$ in $0.9 \%$ $\mathrm{NaCl})$ catheter (100 $\mathrm{mg} \mathrm{kg}^{-1}$ animal).

\section{Nephrectomy}

Nephrectomy was performed on anesthetized rats by ligation (with 4-0 non-absorbable suture) of the renal arteries and veins after dorsal entry through the muscle layer. The incision sites were closed with metal wound clamps (Michel, $11 \times 2 \mathrm{~mm}$ ) after the ligation.

\section{LI-COR live imaging}

Anesthetized rats in a stereotaxic frame had their cranium and upper neck muscles exposed, and a burr hole drilled (same coordinates as i.c.v. cannula placement in ICP recordings) into which a Hamilton syringe (RN 0.40, G27, a20, Agntho's) was inserted $4 \mathrm{~mm}$ into the lateral ventricle. The experiment was initiated with intraventricular injection $\left(1.5 \mu \mathrm{l} \mathrm{s}^{-1}\right)$ of $15 \mu \mathrm{l}$ aCSF containing either vehicle (0.1\% DMSO) or AZE ( $2 \mathrm{mM}$; expected ventricular concentration of $200 \mu \mathrm{M}$ due to dilution in $\sim 150 \mu$ l native CSF). The procedure was repeated after $5 \mathrm{~min}$, but with inclusion of carboxylate dye (10 $\mu \mathrm{M}$; IRDye 800CW, P/N 929-08972, LI-COR Biosciences). In experiments with i.v. delivery of AZE (100 $\mathrm{mg} \mathrm{kg}^{-1}$ animal), these were injected into the tail vein through a catheter (24 G Neoflon, VWR) $25 \mathrm{~min}$ 
prior to carboxylate dye injection. Image acquisition was initiated $1 \mathrm{~min}$ after carboxylate injection and continued for $5 \mathrm{~min}$ with 30s intervals using a Pearl Trilogy Small Animal Imaging System (LI-COR) (800 $\mathrm{nm}$ channel, $85 \mu \mathrm{m}$ resolution). The anesthetized rats were secured during imaging in a custom-made tooth holder to stabilize their head position. The fluorescence signal was determined in a region of interest (ROI) placed at skull landmark lambda as a function of time, and quantified relative to the initial fluorescence intensity obtained at $0.5 \mathrm{~s}$ in a blinded manner. A white field image of the rat head was captured at the end of imaging prior to visualizing the lateral ventricles of the isolated brain hemispheres to verify bilateral carboxylate staining. Data analyses were performed in Image Studio 5.2 (LI-COR Biosciences - GmbH, Nebraska, US).

\section{Radioisotope flux assays}

Isolated rat brains were kept in cold HEPES-aCSF $\left(4^{\circ} \mathrm{C}, \mathrm{pH} 7.35\right)$ for $10 \mathrm{~min}$ prior to isolation of the lateral choroid plexuses. The isolated lateral choroid plexuses were subsequently placed in HEPESaCSF $\left(\mathrm{pH} 7.56,37^{\circ} \mathrm{C}\right)$ for $10 \mathrm{~min}$. The experiments were initiated by choroidal isotope accumulation (1 $\mu \mathrm{Ci} \mathrm{ml}{ }^{-1}{ }^{86} \mathrm{Rb}^{+}, 022-105721-00321-0001$, POLATOM, as a marker for $\mathrm{K}^{+}$transport, and $4 \mu \mathrm{Ci} \mathrm{ml}^{-1}{ }^{3} \mathrm{H}-$ mannitol as an extracellular marker, PerkinElmer) for $2 \mathrm{~min}$ (influx) or $10 \mathrm{~min}$ (efflux). The influx experiments were conducted either in the presence of $2 \mathrm{mM}$ ouabain (O3125, Sigma), $200 \mu \mathrm{M}$ AZE, or in the appropriate vehicle, after which the choroid plexus was swiftly rinsed in cold isotope-free HEPES-aCSF $\left(4^{\circ} \mathrm{C}\right)$ and transferred to a scintillation vial. For the efflux experimentation, the choroid plexus was briefly washed (15 s) in $37^{\circ} \mathrm{C}$ HEPES-aCSF following the isotope accumulation step, and subsequentially transferred (at $20 \mathrm{~s}$ intervals) to different HEPES-aCSF solutions $\left(37^{\circ} \mathrm{C}\right)$ containing either $200 \mu \mathrm{M}$ AZE, $20 \mu \mathrm{M}$ bumetanide (B3023, Sigma), or appropriate vehicle. The efflux medium from each of the solutions was transferred into separate scintillation vials. For both influx and efflux assays, the choroid plexus was dissolved in $100 \mu$ l Solvable (6NE9100, Perkin Elmer) prior to addition of $500 \mu$ l of Ultima Gold ${ }^{T M}$ XR scintillation liquid (6012119, PerkinElmer) and subsequent quantification in a Tri-Carb 2900TR Liquid Scintillation Analyzer (Packard). The ${ }^{86} \mathrm{Rb}^{+}$counts were corrected for ${ }^{3} \mathrm{H}$ 
bioRxiv preprint doi: https://doi.org/10.1101/2022.01.11.475854 this version posted January 12, 2022. The copyright holder for this preprint (which was not certified by peer review) is the author/funder, who has granted bioRxiv a license to display the preprint in perpetuity. It is made available under aCC-BY-NC-ND 4.0 International license.

mannitol counts (extracellular background), and the natural logarithm of the choroid plexus content $A_{t} / A_{0}$ was plotted against time (58) to obtain the ${ }^{86} \mathrm{Rb}^{+}$efflux rate $\left(\mathrm{s}^{-1}\right)$ by linear regression analysis.

\section{Intracellular $\mathrm{Na}^{+}$measurement}

Isolated lateral choroid plexuses were transferred into a recording chamber and perfused with $\mathrm{HCO}_{3}^{-}$ aCSF at room temperature $\left(22 \pm 1^{\circ} \mathrm{C}\right)$ for about $20 \mathrm{~min}$. Subsequently, the $\mathrm{Na}^{+}$-sensitive fluorescent dye SBFI-AM (sodium-binding benzofuran isophthalate acetoxymethyol ester, 2021E, ION Biosciences, dissolved in 20\% Pluronic, F127) was pressure-injected into several regions of the choroid plexus, using a fine-tipped glass micropipette coupled to a pressure application system (PDES nxh, npi electronic, Tamm, Germany). The tissue was subsequently perfused with $\mathrm{HCO}_{3}^{-}-\mathrm{aCSF}(\sim 45 \mathrm{~min})$ to wash out excess dye and allow for de-esterification. Wide-field $\mathrm{Na}^{+}$imaging was obtained with a variable scan digital imaging system (Nikon NIS-Elements v4.3, Nikon $\mathrm{GmbH}$ ) coupled to an upright microscope (Nikon Eclipsle FN-PT, Nikon GmbH). The microscope was equipped with a ×40/N.A. 0.8 LUMPlanFI water immersion objective (Olympus Deutschland $\mathrm{GmbH}$ ) and an orca FLASH V2 camera (Hamamatsu Photonics Deutschland $\mathrm{GmbH}$ ). SBFI was alternately excited at 340 and $380 \mathrm{~nm}$, and emission collected $>440 \mathrm{~nm}$ with a sampling rate of $0.5 \mathrm{~Hz}$. Fluorescence emission was recorded from defined regions of interest (ROI) representing single cells, for $2 \mathrm{~min}$ in $\mathrm{HCO}_{3}{ }^{-}$aCSF under baseline conditions, followed by perfusion with $\mathrm{HCO}_{3}{ }^{-}$-aCSF containing $200 \mu \mathrm{M}$ AZE or $0.02 \%$ DMSO (control) and imaging for another 30min. SBFI signals were analyzed with OriginPro Software (OriginLab Corporation v.9.0). Backgroundcorrection was carried out for each ROI to obtain the fluorescence ratio (F340/F380). Linear regression analyses were performed on control and drug periods in a blinded fashion.

\section{RNAseq}

Choroid plexus (lateral and $4^{\text {th }}$ ) were isolated from 5 AZE-treated and 5 control rats, pooled respectively, and stored in RNAlater ${ }^{\circledast}$ at $-80^{\circ} \mathrm{C}$. The RNA extraction and library preparation were performed by Novogene Company Limited, UK with NEB Next ${ }^{\circledR}$ Ultra ${ }^{\mathrm{TM}}$ RNA Library Prep Kit (NEB, USA) prior to their RNA sequencing (paired-end $150 \mathrm{bp}$, with $12 \mathrm{~Gb}$ output) on an Illumina NovaSeq 6000 
(Illumina, USA). Program parameter settings for library build, mapping, and quantification, together with scripts for the gene annotation and analysis can be found at https://github.com/Sorennorge/MacAulayLab-RNAseq2-Acetazolamide. The 150 base paired-end reads were mapped to Reference genome Rnor_6.0 (Rattus_norvegicus v.103), only including protein coding genes (biotype), using Spliced Transcripts Alignment to a Reference (STAR) RNA-seq aligner (v 2.7.2a) (59). The mapped alignment generated by STAR were normalized to transcripts per million (TPM) (60) with RSEM (v. 1.3.3). The RNA sequencing data for human choroid plexus was obtained from Rodríguez-Lorenzo, (Geo: GSE137619, SRR10134643-SRR10134648) (61), and the RNA sequencing data for mouse choroid plexus was obtained from Lun et al. (Geo: GSE66312, SRR1819706SRR18197014) (62). All human and mouse samples were quality checked with fastqc (63), and then trimmed with Trimmomatic (64) (Slidingwindow:4:20, and minimum length of 35bp). The human and mouse samples were mapped to reference human genome (Homo sapiens GRCh38.104) and mouse reference genome (Mus musculus GRCm39.104), both only including protein coding genes (biotype), with STAR ( $v$ 2.7.2a). The mapped alignment were quantified to TPM using RSEM (v. 1.3.3) and the mean from the human and the mouse samples were used for further analysis.

\section{Ventricular-cisternal perfusion}

Rats were anesthetized, ventilated, and an infusion cannula (Brain infusion kit 2, Alzet) was stereotaxically placed in the right lateral ventricle (as described in ICP measurements), through which a pre-heated $\left(37^{\circ} \mathrm{C}, \mathrm{SF}-28\right.$, Warner Instruments) $\mathrm{HCO}_{3}{ }^{-}$-aCSF containing $1 \mathrm{mg} \mathrm{ml}^{-1}$ TRITC-dextran (tetramethylrhodamine isothiocyanate-dextran, $\mathrm{MW}=150,000 ; \mathrm{T} 1287$, Sigma) was infused at 9

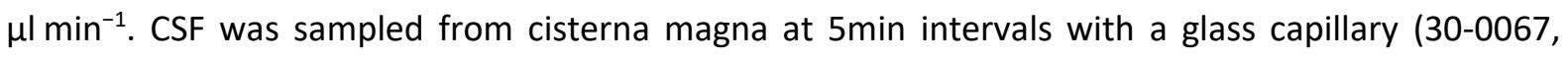
Harvard Apparatus pulled by a Brown Micropipette puller, Model P-97, Sutter Instruments) placed at a $5^{\circ}$ angle ( $7.5 \mathrm{~mm}$ distal to the occipital bone and $1.5 \mathrm{~mm}$ lateral to the muscle-midline). The fluorescent content of CSF outflow was measured in triplicate on a microplate photometer $(545 \mathrm{~nm}$, SyneryTM Neo2 Multi-mode Microplate Reader; BioTek Instruments), and the CSF secretion rate was calculated from the equation: 


$$
V_{p}=r_{i} * \frac{C_{i}-C_{o}}{C_{o}}
$$

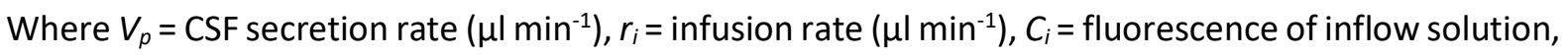
$C_{o}=$ fluorescence of outflow solution. The ventricles were perfused for $80 \mathrm{~min}$, and the production rate over the last $20 \mathrm{~min}$ was used to calculate the average CSF secretion rate for the animal.

\section{Brain water content}

Brains were swiftly isolated from euthanized rats, placed in a pre-weighed porcelain evaporation beaker (olfactory bulbs and medulla oblongata discarded), and immediately weighed. The brain was homogenized in the beaker with a steel pestle prior to oven-drying at $100^{\circ} \mathrm{C}$ for 3 days and subsequent determination of dry brain weights. Brain water contents were calculated from evaporated water, and expressed in $\mathrm{ml}$ water per $\mathrm{g}$ dry brain weight.

\section{ICP and MAP monitoring in awake rats}

KAHA Sciences rat dual pressure telemetric system was implemented for monitoring ICP and MAP in non-anesthetized, awake rats. The implantation was performed as described in (65). Briefly, animals were given $5 \mathrm{mg} \mathrm{kg}^{-1}$ Caprofen (Norodyl Vet, Norbrook), $0.05 \mathrm{mg} \mathrm{kg}^{-1}$ buprenorphine (Tamgesic, Indivior), and $200+40 \mathrm{mg} \mathrm{kg}^{-1}$ sulfadiazin and trimethoprim (Borgal Vet, Ceva) s.c. prior to the surgery and 2 days post-surgery. The incision areas were shaved and sterilized with $0.5 \%$ chlorhexidine (Medic). An abdominal midline incision was made, the abdominal aorta isolated, and the first pressure probe was inserted into the aorta using a bent $23 \mathrm{G}$ needle. It was secured with tissue adhesive (Histoacryl, Enbucrilate; B. Braun) and surgical mesh (PETKM2002, SurgicalMesh; Textile Development Associates). The body of the telemetric device was secured to the abdominal wall, and 4-0 absorbable Vicryl suture (Ethicon) was used to close the abdominal muscles. The protruding second pressure probe was tunneled to the base of the skull using a $6 \mathrm{~mm}$ diameter stainless steel straw (Ecostrawz). 
The animal was placed into the stereotactic frame (Harvard apparatus), and the skull was exposed.

Using $1.2 \mathrm{~mm}$ burr bits, two holes were drilled on the contralateral sides of the skull posterior to bregma. Stainless steel screws (00-96x3/32, Bilaney Consultants $\mathrm{GmbH})$ were inserted into these holes, and served as anchors for stabilizing the system. The second pressure probe was placed epidurally in a third $1.4 \mathrm{~mm}$ drill hole placed between the two screws. The hole was subsequently filled with spongostan (Ethicon), and the probe was secured using surgical mesh and tissue adhesive. Dental impression material (Take 1 Advanced, Kerr) was applied over the catheter and the screw, and the skin incision was closed with non-absorbable 4-0 Ethilonll suture (Ethicon), which was removed 10 days post-surgery. Animals were placed in their cages on the TR181 Smart Pads (Kaha Sciences), and data acquisition obtained at $1 \mathrm{kHz}$ with PowerLab and LabChart software (v8.0, ADInstruments). Data was extracted from LabChart as 6 min average values and outlying data points identified with GraphPad Prism (GraphPad Software). During the experimental series with 1× day AZE treatment, day 5 was discarded from the analysis due to the weekly cage change, which caused a visible disturbance in all measured parameters. The $3 \times$ day dosing experiments were performed on same animals that received $1 \times$ day dosing seven days after recovery from the previous treatment.

\section{Statistics}

All data are presented as average \pm SEM. Statistical significance analysis was performed with GraphPad Prism (GraphPad Software), and $\mathrm{P} \leq 0.05$ was considered statistically significant. 1way ANOVA with Tukey's multiple comparison post hoc test was used in ICP and MAP analyses of nephrectomised, hyperventilated and i.c.v.-infused animals to include comparison with naïve animals. 2 way ANOVA analysis was used in the blood gas analysis, and additional post-hoc analysis with Bonferroni's (intact) or Tukey's (nephrectomised, hyperventilated and i.c.v. infused) multiple comparisons test was performed for $\mathrm{pCO}_{2}$ data. 2 way ANOVA with Bonferroni's multiple comparisons test was also used to analyze the daily $2 \mathrm{~h}$ average patterns in the telemetry experiments. Paired t-test was used to compare the telemetrically measured raw ICP values before and after $3 x$ daily treatment. Unpaired t-tests were 
bioRxiv preprint doi: $h$ ttps://doi.org/10.1101/2022 01.11.475854 t this version posted January 12,2022 . The copyright holder for this preprint (which was not certified by peer review) is the author/funder, who has granted bioRxiv a license to display the preprint in perpetuity. It is made available under aCC-BY-NC-ND 4.0 International license.

used in the rest of the analyses. Significance is represented as asterisks above the bar graphs and represent $\mathrm{P}>0.05=\mathrm{ns}, \mathrm{P} \leq 0.05=*, \mathrm{P} \leq 0.01=* *, \mathrm{P} \leq 0.001=* * *$.

\section{Study approval}

All animal experiments were performed in accordance to the European legislations for the care and use of laboratory animals, and approved by the Danish Animal Experiments Inspectorate (License no. 2016-15-0201-00944 and 2018-15-0201-01595) or the Animal Welfare Office at the Animal Care and Use Facility of the Heinrich Heine University Düsseldorf (institutional act no. 052/05). 


\section{Results}

\section{AZE effectively lowers ICP}

To determine the modulatory effect of AZE on ICP in anesthetized and ventilated rats, AZE was delivered systemically as a bolus i.v. injection during simultaneous recording of the ICP. The base ICP of the experimental rats was $4.2 \pm 0.1 \mathrm{mmHg}, \mathrm{n}=34$. We observed an abrupt spike in ICP immediately after AZE administration (to $133 \pm 6 \%, n=5$ ) with a subsequent gradual decrease of the ICP to $-48 \pm 4 \%$ below the baseline level $2 \mathrm{~h}$ after the injection, $n=5$ (Figure 1A-B). The control animals (bolus injection of vehicle) did not experience the initial ICP peak $(103 \pm 1 \%, n=5)$, and the subsequent timedependent decline in ICP amounted to $-25 \pm 4 \%$ below the baseline level, $n=5$ (Figure 1A-B), which was significantly less than that of the AZE-treated rats $(P<0.01)$. AZE is recognized for its lowering effect on blood pressure (49), which in turn could affect ICP and/or CSF secretion (50). We therefore, in parallel with the ICP measurements, performed recordings of the mean arterial pressure (MAP). The initial MAP was $71.7 \pm 1.3 \mathrm{mmHg}, \mathrm{n}=34$, amongst all the tested rats. The MAP remained stable for the duration of the experiment in both experimental animal groups $(-5 \pm 2 \%$ for AZE treated rats, and $-6 \pm 3 \%$ below baseline for control rats, $n=5, P=0.9$, Figure 1C-D). AZE thus exerts its effect on the ICP in a manner independent of the MAP.

\section{AZE affects the systemic acid-base balance}

As an inhibitor of the carbonic anhydrases, AZE affects the $\mathrm{CO}_{2}-\mathrm{HCO}_{3}{ }^{-}$conversion in the erythrocytes, and systemic delivery of AZE may therefore affect the blood gases in a manner that could indirectly affect CSF secretion or other physiological processes. We therefore monitored the exhaled etCO $\mathrm{CO}_{2}$ of the anesthetized and ventilated experimental rats at a constant rate. In contrast to the control animals $(100 \pm 1 \%, n=5)$, administration of AZE caused an abrupt decrease in etCO ${ }_{2}$ (by $-32 \pm 1 \%, n=5$, $\mathrm{P}<0.001$ ), which remained reduced (to $-9 \pm 1 \%$ below the baseline et $\mathrm{CO}_{2}$ ) at the termination of the experiment (Figure 1E). This shift in etCO $\mathrm{CO}_{2}$ was reflected in the blood $\mathrm{pCO}_{2}$, which remained stable in control animals but increased dramatically in rats treated with AZE (from $5.2 \pm 0.2 \mathrm{kPa}$ to $10.1 \pm 0.2$ 
$\mathrm{kPa} 2 \mathrm{~h}$ after AZE treatment, $\mathrm{n}=5, \mathrm{P}<0.001$, Figure $1 \mathrm{~F})$. Consequently, the blood $\mathrm{pH}$ decreased in AZE animals compared to controls (see all blood gas analyses in Supplementary Table S1). Taken together, the decreased exhaled et $\mathrm{CO}_{2}$, increased blood $\mathrm{pCO}_{2}$, and decreased $\mathrm{pH}$ indicate a severe respiratory acidosis due to carbonic anhydrase inhibition in the pulmonary endothelium and the circulating erythrocytes. The blood $\mathrm{HCO}_{3}^{-}$levels decreased in the AZE treated experimental rat group (from $23.0 \pm 0.4 \mathrm{mM}$ to $19.3 \pm 0.3 \mathrm{mM}, \mathrm{n}=4)$ to a larger extent $(P<0.05)$ than what was observed in the control group (from $23.7 \pm 0.4 \mathrm{mM}$ to $21.1 \pm 0.6 \mathrm{mM}, \mathrm{n}=5$, Figure $1 \mathrm{G}$ ), suggesting an accompanying metabolic acidosis. Systemic administration of AZE thus causes severe acid-base disturbances, which could indirectly affect ICP and/or CSF secretion.

\section{AZE exert its effect on ICP independently of the systemic water homeostasis}

An AZE-induced change in systemic $\mathrm{HCO}_{3}{ }^{-}$levels is likely to occur via the inhibitory action of AZE on carbonic anhydrases in the kidney proximal tubule epithelium (47). Such a process will impair $\mathrm{HCO}_{3}{ }^{-}$ reabsorption and induce diuresis (66), which could lead to ICP reduction. To resolve whether AZE indirectly exerts its effect on ICP via its action on the kidney, we determined the effect of AZE administration in nephrectomized rats (Figure 2A). AZE treatment reduced the ICP of nephrectomized rats by $(-47 \pm 3 \%, n=4$, Figure $2 B)$, which is similar to what was observed in non-nephrectomized rats (compare with $-48 \pm 4 \%$, Figure $1 \mathrm{~A}$ ). The control treatment caused similar ICP reductions in the rats whether or not the animals had undergone nephrectomy (compare $-27 \pm 6 \%, n=4$, Figure $2 B$ with $25 \pm 4 \%, \mathrm{n}=5$ in Figure 1A). Nephrectomy caused a similar decrease in MAP in all experimental rats, irrespective of AZE administration (-30 $\pm 9 \%$ in the control group, and $-31 \pm 5 \%$ in the AZE group, $n=4$ of each, $\mathrm{P}=0.9$, Figure 2C-D). Likewise, AZE-induced changes in etCO $\mathrm{CO}_{2}$ and $\mathrm{pCO}_{2}$ were indistinguishable between nephrectomized and intact animals (Figure 2E-F, all blood gas analyses available in Supplementary Table S2). The baseline $\mathrm{HCO}_{3}^{-}$levels were reduced in both groups of experimental animals (compare $23.4 \pm 0.3 \mathrm{mM}$ in intact animals, $\mathrm{n}=9$ to $21.6 \pm 0.5 \mathrm{mM}, \mathrm{n}=8$ in nephrectomized animals, $\mathrm{p}<0.01$ ), probably due to absent $\mathrm{HCO}_{3}^{-}$reabsorption by the nephrectomized kidney. The blood $\mathrm{HCO}_{3}^{-}$levels declined during the course of the experiments (as 
observed in the intact animals, Figure $1 \mathrm{G}$ ), but with no AZE-induced changes in $\mathrm{HCO}_{3}^{-}$reabsorption in the nephrectomized rats (Fig. 2G). Taken together, the results indicate that the effect of AZE on ICP occurs independently of its inhibitory action on kidney function (including its $\mathrm{HCO}_{3}^{-}$handling) and thus the systemic water homeostasis.

Hyperventilation does not prevent AZE's ability to lower ICP

To determine whether AZE exerts its effect on ICP in an indirect manner via altered $\mathrm{CO}_{2}$ dynamics in the blood, we attempted to prevent the AZE-induced $\mathrm{CO}_{2}$ retention in the blood by mechanical hyperventilation of the animals during the experimental procedure. Blood gas analysis (Supplementary Table S3) revealed that hyperventilation caused a $3.5 \mathrm{kPa}$ reduction in $\mathrm{pCO}_{2}$ in control animals by the end of experiment (from $5.4 \pm 0.1 \mathrm{kPa}, \mathrm{n}=5$ in intact animals to $1.9 \pm 0.1 \mathrm{kPa}, \mathrm{n}=4$ in hyperventilated, $\mathrm{P}<0.001$ ), but a $1.6 \mathrm{kPa}$ reduction in AZE-treated animals (from $10.1 \pm 0.2 \mathrm{kPa}, \mathrm{n}=5$ in intact to $8.4 \pm 0.3 \mathrm{kPa}, \mathrm{n}=4$ in hyperventilated, $\mathrm{P}<0.05$, Figure $3 \mathrm{~A})$. Hyperventilation thus did not revert the AZE-induced change in $\mathrm{pCO}_{2}$ to the level of the control animals (Figure $3 \mathrm{~A}$ ). Despite the partial prevention of the AZE-induced elevation of blood $\mathrm{CO}_{2}$ levels by hyperventilation, AZE treatment caused a reduction of ICP $(-65 \pm 3 \%, n=4$, Figure $3 B-C)$ that was augmented compared to that obtained with conventional ventilation $(-48 \pm 4 \%, n=5$, Figure $1 \mathrm{~A}, \mathrm{P}<0.05)$, yet the same was not observed in the hyperventilated control animals (compare $-26 \pm 4 \%, n=4$ Figure $3 C$ with $-25 \pm 4 \%$, $n=5$ in Figure $1 A)$. Hyperventilation reduced the MAP to a similar extent $(P=0.3)$ in both the control $(-30 \pm 1 \%, n=4)$ and AZE $(-24 \pm 5 \%, n=4)$ group (Figure $3 E-F)$, supporting the finding from Figure 1D that AZE treatment did not reduce the MAP. Taken together, AZE-induced increase in blood $\mathrm{pCO}_{2}$ does not contribute to ICP reduction.

Intraventricular AZE prevents systemic disturbances, but retains its ICP lowering effect

AZE thus facilitates a reduction in ICP independently of its effect on blood pressure, kidney function, and blood gas content. To obtain a scenario in which AZE could be administered without systemic disturbances, we applied AZE intracereboventricularly (i.c.v.). AZE application directly into the lateral 
ventricle of anesthetized rats did not disturb the MAP (Figure 4A-B), the blood $\mathrm{pCO}_{2}$ (Figure $4 \mathrm{C}$ ), the blood $\mathrm{HCO}_{3}{ }^{-}$concentration (Figure 4D), or any other blood gas parameter including $\mathrm{pH}$ (Supplementary Table S4). Nevertheless, AZE delivery in this manner caused an ICP reduction $(-51 \pm 5 \%, n=4)$, significantly larger than that of the control group $(-16 \pm 7 \%, n=4, P<0.01$, Figure $4 E-F)$, but similar to that obtained upon i.v. injection of the inhibitor $(48 \pm 4 \%, n=5$, see Figure $1 A)$. In addition, the initial AZE-mediated ICP peak observed with systemic delivery of AZE (Figure 1A) was absent with the i.c.v. delivery of the inhibitor (Figure 4E). AZE administration directly into the brain thus lowers the ICP equally effectively as with systemic delivery, but independently of the AZE-mediated modulation of systemic parameters that could indirectly affect ICP. AZE therefore appears to serve its modulatory action on the ICP via a pathway residing in the brain tissue.

\section{AZE treatment lowers CSF flow in anesthetized rats}

To determine if the AZE-mediated lowering of the ICP occurred by a reduction in the rate of CSF secretion, we assessed this parameter with a swift, minimally invasive approach based on imaging fluorescent dye flow in the ventricles of anesthetized rats (67) (Figure 5A). The fluorescent dye movement was reduced by $40 \%$ upon AZE treatment, whether the inhibitor was delivered i.c.v. (compare $0.16 \pm 0.01$ a.u. $\min ^{-1}, \mathrm{n}=4$ with $0.10 \pm 0.02$ a.u. $\min ^{-1}, \mathrm{n}=4, \mathrm{P}<0.05$, Figure $5 \mathrm{~B}$ ) or i.v. (compare $0.16 \pm 0.02$ a.u. $\min ^{-1}, n=6$ with $0.09 \pm 0.01$ a.u. $\min ^{-1}, n=4, P<0.05$, Figure 5 C). AZE thus exerts its effect on the ICP, at least in part, by reducing the CSF secretion rate.

\section{AZE does not affect the transport rate of $\mathrm{Na}^{+} / \mathrm{K}^{+}$-ATPase or NKCC1}

AZE-dependent inhibition of carbonic anhydrases indirectly inhibits $\mathrm{HCO}_{3}^{-}$transporters by reducing the available substrate, and most likely exerts its effect on CSF secretion by affecting some of these transport mechanisms located on both the sides of the CSF secreting choroid plexus epithelium (35). However, AZE could serve indirect effects on other choroidal transport mechanisms, such as its proposed action on the $\mathrm{Na}^{+} / \mathrm{K}^{+}$-ATPase (14). To determine a putative AZE-mediated reduction in transport rate of other key CSF secreting transporters, we performed ex vivo radioactive ${ }^{86} \mathrm{Rb}^{+}$efflux 
and influx assays, which serve as a functional read-out for the activity of NKCC1 and $\mathrm{Na}^{+} / \mathrm{K}^{+}-$ATPase, respectively. The NKCC1 activity was determined as the efflux rate of ${ }^{86} \mathrm{Rb}^{+}$(serving as a congener for the transported $\mathrm{K}^{+}$) that is sensitive to the NKCC1 inhibitor bumetanide (Figure $6 \mathrm{~A}$ ). The ${ }^{86} \mathrm{Rb}^{+}$efflux rate constant was diminished by $\sim 50 \%$ by inclusion of bumetanide (compare $0.33 \pm 0.02$ with $0.17 \pm 0.01 \mathrm{~min}^{-1}, \mathrm{n}=6$ of each, $\mathrm{P}<0.001$, Figure $6 \mathrm{~A}-\mathrm{B}$ ). Exposure to AZE did not affect the ${ }^{86} \mathrm{Rb}^{+}$efflux rate (compare $0.32 \pm 0.02$ in control with $0.34 \pm 0.02 \mathrm{~min}^{-1}$ in AZE, $\mathrm{n}=6$ of each, $P=0.8$, Figure $6 C-D$ ). $\mathrm{Na}^{+} / \mathrm{K}^{+}$-ATPase activity was monitored as the ouabain-sensitive influx of ${ }^{86} \mathrm{Rb}^{+}$. Application of the selective $\mathrm{Na}^{+} / \mathrm{K}^{+}$-ATPase inhibitor oubain $(2 \mathrm{mM}$ ) reduced the influx rate by $70 \%$ (compare $2772 \pm 501$ cpm in control with $794 \pm 217 \mathrm{cpm}$ in ouabain, $\mathrm{n}=6$ of each, $\mathrm{P}<0.01$, Figure $6 \mathrm{E})$, whereas AZE did not alter the uptake rate (compare $2141 \pm 119$ in control with $2168 \pm 361 \mathrm{cpm}$ in AZE, $n=6$ of each, $P=0.9$, Figure 6F). These data indicate that the AZE-mediated reduction in the CSF secretion rate does not occur via indirect modulation of the NKCC1 or the $\mathrm{Na}^{+} / \mathrm{K}^{+}$-ATPase, and therefore must be via the various $\mathrm{HCO}_{3}{ }^{-}$transporters located in the choroid plexus epithelium.

To reveal the choroidal $\left[\mathrm{Na}^{+}\right]_{i}$ dynamics upon AZE treatment, acutely isolated ex vivo choroid plexus tissue was loaded with the $\mathrm{Na}^{+}$-sensitive fluorescent dye SBFI, and monitored by wide-field SBFI imaging. The SBFI signal stayed stable during the AZE exposure (Figure $6 \mathrm{G}-\mathrm{H}$ ), suggesting that the $\left[\mathrm{Na}^{+}\right]_{\mathrm{i}}$ remained undisturbed during AZE's inhibitory action. These data support the notion that NKCC1 and the $\mathrm{Na}^{+} / \mathrm{K}^{+}$-ATPase activity occurred uninterrupted in the presence of AZE. Of note, an AZE-mediated reduction of the CSF secretion rate with no concomitant changes in $\left[\mathrm{Na}^{+}\right]_{i}$ could occur by inhibition of the various $\mathrm{HCO}_{3}{ }^{-}$transporters located on both epithelial membranes of the choroid plexus.

AZE does not reduce choroidal expression of carbonic anhydrases or key transporters implicated in CSF secretion

To assess carbonic anhydrase expression in the rat choroid plexus, and to evaluate whether chronic AZE treatment caused changes in the functional properties of the choroid plexus related to CSF secretion, we performed RNAseq analysis on choroid plexus obtained from animals that received AZE 
(or control solution) once daily for 7 days. 13 different CA isoforms were expressed in the rat choroid plexus, with CA2 being expressed nearly one order of magnitude higher than the subsequent CA14 (Table 1). Comparison of the carbonic anhydrase isoform transcripts detected in rat choroid plexus with those obtained from mouse (62) and human (61) choroid plexus, revealed that seven were detected in all three species at moderate to high levels (CA2, CA14, CA12, CA11, CA13, CA5B, CA3 in order of abundance), which suggests their functional importance in the tissue. CA4 was detected in rat and human choroid plexus, whereas two isoforms (CA6, CA9) were found only in the rat choroid plexus. Three isoforms were below reliable detection level in the rat choroid plexus (CA1, CA7, CA8). Chronic AZE treatment did not cause a general down regulation of the choroidal CAs, although CA4 abundance was reduced to approximately half. In contrast, a compensatory elevation seemed to occur for transcripts encoding CA9 and CA12, as well as for two of the key choroidal transport mechanisms, the $\mathrm{Na}^{+} / \mathrm{K}^{+}$-ATPase and NBCe2 (Table 2). Therefore, chronic exposure of AZE does not appear to provide a sustained reduction of the choroidal CSF secretion apparatus.

\section{Chronic exposure to AZE does not provide prolonged effects on the brain water content or CSF} secretion rate

It is evident that acute intake of AZE reduces the ICP, which, at least partially, arises from AZEmediated reduction in CSF secretion rate. However, the limited efficacy in the clinical setting called for an evaluation of AZE's effect upon chronic intake. To determine whether prolonged exposure to AZE altered the CSF dynamics, experimental rats were treated with AZE (or control solution) once daily for 7 days. The brain water content obtained $24 \mathrm{~h}$ after last treatment remained undisturbed following such treatment (compare $3.67 \pm 0.03 \mathrm{ml} \mathrm{g}^{-1}$ dry brain weight in control animals to $3.69 \pm 0.01 \mathrm{ml} \mathrm{g}^{-1}$ dry brain weight in animals treated with $A Z E, n=5$ of each, $P=0.5$, Figure $7 A$ ). This notion of undisturbed fluid dynamics after chronic exposure to AZE was underscored by the similar CSF secretion rate obtained the day following completion of the treatment regime with the ventricularcisternal perfusion assay (67) in treated animals $\left(5.4 \pm 0.3 \mu \mathrm{m} \mathrm{m}^{-1}\right)$ versus control animals $(4.7 \pm 0.6$ 
$\mu \mathrm{l} \min ^{-1}, \mathrm{n}=4$ of each, $\mathrm{P}=0.4$, Figure 7B-C). Chronic delivery of AZE (once daily) therefore does not appear to lead to a sustained ( $24 \mathrm{~h}$ ) reduction of brain fluid content or secretion thereof.

\section{Chronically administered AZE has a short-lived effect on ICP}

To monitor the physiological impact of AZE treatment as a function of time in awake and freely moving rats, we monitored the ICP and MAP simultaneously during AZE administration by employing Kaha telemetric dual pressure transmitters. Following implantation of the device, the ICP declined from $6.0 \pm 0.7 \mathrm{mmHg}$ on $1^{\text {st }}$ day post-surgery to a stable level around $3.5 \pm 0.3 \mathrm{mmHg} 10$ days post-surgery, $\mathrm{n}=8$ (Figure $8 \mathrm{~A}$ ), a pattern that was mimicked by the heart rate (from $413 \pm 7 \mathrm{bpm}$ to $338 \pm 9 \mathrm{bpm}$, $\mathrm{n}=8$, Figure $8 \mathrm{~B})$. The MAP was stable during this recovery time $(91 \pm 3 \mathrm{mmHg}$ post-surgery, and $94 \pm 2$ $\mathrm{mmHg}$ on day $10, n=8$, Figure $8 \mathrm{C}$ ), but day-night time oscillations were not visible until 7 days postsurgery, confirming that a recovery period of at least 7 days is required prior to collection of physiological data.

At the termination of the recovery period, the $72 \mathrm{~h}$ average ICP for the experimental rats was $3.8 \pm 0.4$ $\mathrm{mmHg}, \mathrm{n}=8$, and not significantly different between the two experimental groups, $\mathrm{P}=0.8$ (Figure 8D). The treatment period was initiated by p.o. administration of AZE (or control solution) and repeated every $24 \mathrm{~h}$ for 6 days, during which the ICP and MAP was monitored continually. The ICP pattern observed in the control rats resembled that of the rats prior to initiation of the treatment regime (Supplementary Figure 1A). The ICP fluctuated with the diurnal cycle, but deflected more in rats exposed to AZE compared to the control rats (Figure 8E) with a significantly higher AZE-induced ICP reduction $(-1.6 \pm 0.1 \mathrm{mmHg}, \mathrm{n}=4)$ than that observed in the control group $(-0.5 \pm 0.1 \mathrm{mmHg}, \mathrm{n}=4$, $\mathrm{P}<0.001$ ), Figure 8F. The AZE-mediated ICP-reduction lasted for approximately $10 \mathrm{~h}$ post-treatment (Figure 8G), after which the ICP of the AZE-treated rats matched that of the control rats (compare $111 \pm 3 \%$ of baseline, $n=4$ for AZE rats at $10-12 \mathrm{~h}$ post-treatment with $116 \pm 3 \%$ of baseline, $n=4$, $P=0.2)$. An identical pattern was observed with the subsequent AZE administration the following days (Figure 8G). 
To determine whether the AZE-mediated ICP deflection originated from a reduced rate of CSF secretion, as observed in the acutely treated animal experimental protocols, we measured the CSF secretion rate with the fluorescent imaging technique employed in Figure 5A. This swift protocol allowed us to resolve the CSF secretion rate at exactly $2-3 \mathrm{~h}$ after the last of the six AZE (or control solution) doses was administered. The rate of CSF secretion was reduced $50 \%$ compared to that obtained in the control rats (compare $0.18 \pm 0.02$ a.u. $\min ^{-1}, \mathrm{n}=6$ with $0.09 \pm 0.02$ a.u. $\min ^{-1}, \mathrm{n}=5$, $\mathrm{P}<0.01$, Figure $8 \mathrm{H}-\mathrm{I})$. These data support the notion that AZE-mediated reduction in the CSF secretion rate underlies its modulatory effect on ICP.

The AZE-mediated reduction in ICP was not mirrored in change of MAP or heart rate. The MAP of the experimental rats was $93 \pm 2 \mathrm{mmHg}$ ( $n=8$, Supplementary Figure 1B) prior to initiation of the treatment period, and were indistinguishable between the AZE and the control group throughout the experimental period (Supplementary Figure 1C). Same was observed for the heart rate, with the baseline heart rate of $343 \pm 12 \mathrm{bpm}$ ( $n=8$, Supplementary Figure 1D), and no AZE-mediated effect on this parameter (Supplementary Figure 1E). These data suggest that AZE effectively reduces the ICP in awake and freely moving rats in a manner independent of cardiovascular effects.

To resolve whether a frequent dosing regimen can provide the sustained decrease in ICP required for clinical efficacy of such pharmacological treatment, the rats were dosed $3 \times$ daily at intervals of 7-710h. The maximal AZE-mediated ICP reduction was similar to that obtained with a single daily dose (compare $-1.7 \pm 0.2 \mathrm{mmHg}$ for $3 \times$ day treatment (Figure $8 \mathrm{~J}$ ) with $-1.6 \pm 0.1 \mathrm{mmHg}$ for $1 \times$ treated animals (Figure $8 \mathrm{~F}$ ), $\mathrm{n}=4$ in each group, $\mathrm{P}=0.8$ ). The $3 \times$ daily dosing, however, provided a sustained decrease in ICP (Figure 8K), which at no point reached the baseline levels (compare $4.8 \pm 0.3 \mathrm{mmHg}$ baseline ICP with $3.9 \pm 0.3 \mathrm{mmHg}$ ICP just prior to any of the next AZE treatments, $n=12$ ( 4 biological replicates at 3 different time points) in each of the three groups, $\mathrm{P}<0.01$, Figure $8 \mathrm{~L}$ ). In contrast, the control group ICP remained at baseline throughout the experiment (compare $5.8 \pm 0.4 \mathrm{mmHg}$ baseline ICP with $5.8 \pm 0.3 \mathrm{mmHg}$ before each treatment with control solution, $\mathrm{n}=4$ in each group, $\mathrm{P}=0.7$ ). 
bioRxiv preprint doi: https://doi.org/10.1101/2022.01.11.475854; this version posted January 12, 2022. The copyright holder for this preprint (which was not certified by peer review) is the author/funder, who has granted bioRxiv a license to display the preprint in perpetuity. It is made available under aCC-BY-NC-ND 4.0 International license.

Regular administration with AZE during the day thus ensures a sustained ICP reduction of the experimental rats. 


\section{Discussion}

Here, we provide evidence for AZE's ability to reduce ICP in an in vivo rodent model, and showcase that this outcome arises from AZE's direct action on the CSF secretory machinery, and not via modulation of other physiological processes that may indirectly affect CSF secretion. We demonstrate that AZE's ability to lower ICP and reduce the rate of CSF secretion is short lasting, and thus confirm the necessity of frequent dosing in the clinical setting.

AZE has been demonstrated to reduce the CSF secretion rate in various species (16-31), irrespective of its route of delivery (i.v. or i.c.v.), as AZE can cross the cell membrane and reach the choroidal carbonic anhydrases. The present study confirmed that AZE reduces the CSF secretion rate to a similar extent (40\%) whether administered i.v., i.c.v., or p.o. The AZE-mediated reduction in CSF secretion did not occur via an effect on the transport activity of the $\mathrm{Na}^{+} / \mathrm{K}^{+}$-ATPase or the NKCC1, which are both involved in the CSF secretion $(21,22,67)$, but AZE most likely acts via its effect on various $\mathrm{HCO}_{3}{ }^{-}$ transporters localized in the choroid plexus and implicated in CSF secretion (35). However, it remained unresolved if such modulation of the CSF secretion rate is directly represented in a change in ICP and/or ventricular volume. The latter two parameters do not necessarily go hand in hand, as exemplified in idiopathic intracranial hypertension, in which the ICP is elevated without enlarged ventricles (12), and, in contrast, normal pressure hydrocephalus, in which the ventricles are enlarged, but an ICP elevation is absent or minor (68). The etiology of these diseases is not fully understood, but AZE treatment may still be employed to treat the symptoms in these patient groups $(12,69)$, despite this approach being questioned by several clinical trials $(8,9)$.

We demonstrate here that delivery of AZE to healthy experimental rats led to a $40 \%$ reduction of their ICP, irrespective of the route of administration (i.v., i.c.v., or p.o. by gavage), and of whether the animals were under anesthesia or freely moving. This finding is in line with earlier studies that validated AZE's efficacy in lowering the ICP $(13,14)$, but contrasts a study on sedated rats in which no difference in ICP was observed upon AZE delivery either s.c. or p.o. (in Nutella), when controlling for 
solution osmolarity (15). The route of AZE administration and/or the lack of mechanical ventilation during the experimental procedure may have caused the difference in observations. In an animal model of hemorrhagic stroke, AZE was shown to prevent ICP spikes, without reducing the average ICP (70), whereas in a rat model of intracerebral haemorrhage, AZE reduced the brain water content and improved the functional outcome (71).

In the current study we demonstrated that a significant decrease in ICP is observed $>2 \mathrm{~h}$ after p.o. AZE administration in awake rats - a comparable effect to that observed in patients (72). CSF secretion measurements at this exact time point revealed an underlying robust reduction in CSF secretion, which aligned well with that observed upon acute delivery of AZE (i.v. or i.c.v.) in anesthetized rats. Telemetric ICP measurements provided important insight into AZE's mode of action, which could be employed for designing clinical treatment regimens. Reliable and stable ICP measurements in awake rats were observed seven days post-surgery. A daily single dose of AZE, equivalent to a clinically employed $1 \mathrm{~g}$ single dose in humans $(12,15)$, was effective in lowering the ICP. Yet, the ICP returned to baseline within 10-12 $\mathrm{h}$ after the treatment. This lack of a prolonged effect of repeated single daily AZE doses was reflected in identical brain water content in the two experimental groups and an undisturbed rate of CSF secretion obtained the day after the final dosing, and supported by lack of downregulation of choroidal transcripts encoding carbonic anhydrase or those encoding transport proteins involved in CSF secretion. Delivery of AZE at regular intervals $3 \times$ daily, rather than once daily, led to a significant decrease of the ICP throughout the $24 \mathrm{~h}$ cycle, although upon discontinued treatment, the ICP returned to baseline levels. This finding suggests that frequent dosing and strict patient compliance are crucial for effective symptomatic relief of elevated ICP via treatment with AZE.

The AZE-mediated reduction in ICP appears to be a direct result of reduced CSF secretion. Such reduction of CSF secretion can occur directly by inhibition of the carbonic anhydrases in the choroid plexus. We detected expression of the CA isoforms 2, 14, 4, 12, 11, 6, 13, 9, 5B, 3 (in order of expression level) in the rat choroid plexus (Figure 9), the majority of which are detected at the transcript level in mouse and human choroid plexus as well (except CA6, CA9). Some of these choroidal CA isoforms 
(CA2, CA3, CA9, CA12, CA14) have been verified at the protein level (42-46), but their individual quantitative contribution to CSF secretion remains unresolved. AZE-mediated reduction of ICP could, however, occur indirectly by affecting carbonic anhydrases in other tissues and cell types in the body. In this manner, AZE has been proposed to affect blood pressure $(48,49)$, which could reduce blood flow to the choroid plexus $(23,73)$, and lead to a decrease in the CSF secretion rate $(50)$. Despite the robust AZE-induced ICP reduction, we did not detect an AZE-mediated decline in the MAP whether delivered i.v. or i.c.v. to anaesthetized rats or p.o. to freely moving rats with telemetric monitoring of their MAP. AZE administration reduced blood $\left[\mathrm{HCO}_{3}{ }^{-}\right]$, which, in itself, could affect the transport rate of the choroidal $\mathrm{HCO}_{3}{ }^{-}$transporters supporting the $\mathrm{CSF}$ secretion (40), and thus indirectly lower the CSF secretion. This AZE-mediated $\left[\mathrm{HCO}_{3}^{-}\right]_{\text {blood }}$ modulation was, however, abolished with i.c.v. delivery of AZE or upon functional nephrectomy of the experimental rats prior to i.v. delivery of AZE, while the ICP reduction endured in both of these experimental paradigms. The ability of AZE to reduce ICP via a decrease of the rate of CSF secretion thus occurred independently of its potential effect on blood pressure and kidney function.

Administration of AZE by the i.v. route caused an initial peak in ICP prior to the subsequent gradual decline. This peak was mirrored by a decrease in the exhaled $\mathrm{CO}_{2}$ and thus an elevated blood $\mathrm{pCO}_{2}$. Such abrupt increase in $\mathrm{pCO}_{2}$ may cause intracranial vasodilation (74), which could have caused the observed peak in ICP, similar to that observed upon a switch from $100 \% \mathrm{O}_{2}$ inhalation to $30 \% \mathrm{CO}_{2}$ in experimental cats (27). In support of its vascular origin, the elevated $\mathrm{pCO}_{2}$ and the resulting ICP peak was absent in the experimental rats that had AZE administered through the i.c.v. route. The AZEmediated elevation in blood $\mathrm{pCO}_{2}$ upon systemic application remained throughout the duration of the experiment. Organisms usually hyperventilate to correct for $\mathrm{pCO}_{2}$ elevation. Mechanical hyperventilation of the experimental rats reduced the blood $\mathrm{pCO}_{2}$ in both control rats and those exposed to AZE compared to rats with 'normal' ventilation parameters. Nevertheless, the AZE-induced ICP reduction remained intact - it was even slightly more pronounced. The latter finding suggests that AZE treatment in combination with the hyperventilation, sometimes employed clinically to treat 
elevated ICP (54), may serve as complementary tools to manage ICP. However, this additive effect is possibly caused by secondary mechanisms, like $\mathrm{pCO}_{2}$-mediated reduction in cerebral blood flow (23), as it was shown that CSF secretion did not differ between animals with 'normal' ventilation and with hyperventilation (29). Taken together, AZE-mediated ICP reduction does not arise from the increase in $\mathrm{pCO}_{2}$.

In conclusion, AZE reduces the ICP in healthy rats via its ability to decrease the CSF secretion rate. AZE exerts its effect on the CSF secretion machinery in a direct manner, most likely by targeting the choroidal carbonic anhydrases. These enzymes modulate the substrate availability for the $\mathrm{HCO}_{3}{ }^{-}$ transporters that are highly expressed in the choroid plexus and known to act as key contributors to CSF secretion across this tissue $(35,40,41)$. A non-selective CA inhibitor like AZE affects carbonic anhydrases in all other tissues and cell types in the body, which causes the many unpleasant side effects observed with usage of this inhibitor (10). However, these actions do not, as such, appear to affect the CSF secretion rate or the ICP. These findings provide promise of future selective targeting of choroidal carbonic anhydrases in the search for a pharmacological approach to reduce ICP elevation in patients experiencing any of the many pathologies demonstrating this feature. 


\section{Conflict of interest}

The authors declare they have no competing interest.

\section{Funding}

The study was supported by Novo Nordisk Foundation tandem grant (to NM), Brødrende Hartmann's grant (to NM), Lundbeck Foundation (thematic grant and ascending investigator grant (to NM) and post-doc grant (to TLTB)), the Carlsberg Foundation (to NM), Læge Sofus Friis scholarship (to NM), DFG (FOR2795, Ro2327/13-1; to CRR)

\section{Author contributions}

N.M., D.B., E.K.O., C.R.R. designed the research; D.B., E.K.O., J.H.W., T.L.T.B., E.C., S.N.A., N.J.G. executed the experiments/analyzed data. N.M., D.B. drafted the manuscript. All authors participated in the finalization of the manuscript.

\section{Acknowledgements}

We thank laboratory manager Trine Lind Devantier, Department of Neuroscience, Faculty of Health and Medical Sciences, University of Copenhagen for technical assistance. We also thank veterinarians Maria Mathilde Haugaard and Karsten Pharao Hammelev from the Department of Experimental Medicine, Faculty of Health and Medical Sciences, University of Copenhagen for their input on optimizing the survival surgical procedures. 


\section{References:}

1. Fernando SM et al. Diagnosis of elevated intracranial pressure in critically ill adults: Systematic review and meta-analysis. BMJ 2019;366(14225).

2. Rangel-Castillo L, Robertson C. Management of Intracranial Hypertension. Crit Care Clin 2006;22(4):713-32.

3. del Bigio MR, di Curzio DL. Nonsurgical therapy for hydrocephalus: A comprehensive and critical review. Fluids Barriers CNS 2016;13(3).

4. Supuran C. Carbonic Anhydrases as Drug Targets - An Overview. Curr. Top. Med. Chem. 2007;7(9):825-833.

5. Sneader W. Drug Discovery: A History. Wiley \& Sons; 2005, p.390.

6. Coppen AJ, Russell GFM. Effect of Intravenous Acetazolamide on Cerebrospinal Fluid Pressure. Lancet 1957;270(7002).

7. Libenson MH, Kaye EM, Rosman NP, Gilmore HE. Acetazolamide and furosemide for posthemorrhagic hydrocephalus of the newborn. Pediatric Neurology 1999;20(3).

8. Piper RJ et al. Interventions for idiopathic intracranial hypertension. Cochrane Database Syst Rev. 2015;CD003434(8).

9. Whitelaw A et al. Diuretic therapy for newborn infants with posthemorrhagic ventricular dilatation. Cochrane Database Syst Rev 2001;CD002270(2).

10. Schmickl CN et al. effects of acetazolamide: a systematic review and meta-analysis assessing overall risk and dose dependence. BMJ Open Respir Res. 2020;7(1).

11. Jensen RH et al. Awareness, Diagnosis and Management of Idiopathic Intracranial Hypertension. Life 2021;11(7):718.

12. Kaufman DI, Friedman DI. Should Acetazolamide Be the First-Line Treatment for Patients With Idiopathic Intracranial Hypertension?. J Neuroophthalmol 2017;37(2):182-186.

13. Malkinson TJ et al. Induced changes in intracranial pressure in the anesthetized rat and rabbit. Brain Res Bull 1985;15(3):321-8. 
14. Uldall $\mathrm{M}$ et al. Acetazolamide lowers intracranial pressure and modulates the cerebrospinal fluid secretion pathway in healthy rats. Neurosci Lett 2017;645:33-39.

15. Scotton WJ et al. Topiramate is more effective than acetazolamide at lowering intracranial pressure. Cephalalgia 2019;39(2):209-218.

16. Rubin R et al. The Production of Cerebrospinal Fluid in Man and Its Modification by Acetazolamide. J Neurosurg 1966;25(4):430-6.

17. Carrion E et al. Use of acetazolamide to decrease cerebrospinal fluid production in chronically ventilated patients with ventriculopleural shunts. Arch Dis Child 2001;84(1):68-71.

18. Pollay M et al. Extracorpeal perfusion of choroid plexus. J Appl Physiol 1972;32(5):612-17. 19. Holloway LS, Cassin S. Effect of acetazolamide and ouabain on CSF production rate in the newborn dog. Am J Physiol 1972;223(3):503-6.

20. Mccarthy K, Reed D. The effect of acetazolamide and furosemide on cerebrospinal fluid production and choroid plexus carbonic anhydrase activity. J Pharmacol Exp Ther 1974;189(1):194201.

21. Davson H, Segal MB. The effects of some inhibitors and accelerators of sodium transport on the turnover of 22Na in the cerebrospinal fluid and the brain. J Physiol. 1970;209(1):131-153.

22. Welch K. Secretion of cerebrospinal fluid by choroid plexus of the rabbit. Am J Physiol 1963;205:617-24.

23. Faraci FM et al. Vascular effects of acetazolamide on the choroid plexus. J Pharmacol Exp Ther 1990;254(1):23-7.

24. Vogh BP, Langham MR. The effect of furosemide and bumetanide on cerebrospinal fluid formation. Brain Res 1981;221(1):171-83.

25. Maren T, Broder L. The role of carbonic anhydrase in anion secretion into cerebrospinal fluid. J Pharmacol Exp Ther 1970;172(2):197-202.

26. Ames 3rd A et al. Effects of $\mathrm{pCO}_{2}$ acetazolamide and ouabain on volume and composition of choroid-plexus fluid. J Physiol 1965;181(3):516-24. 
27. Tschirgi R et al. Inhibition of cerebrospinal fluid formation by a carbonic anhydrase inhibitor, 2acetylamino-1,3,4-thiadiazole-5-sulfonamide (diamox). Proc Soc Exp Biol Med 1954;87(2):373-6.

28. Melby J et al. Effect of acetazolamide and furosemide on the production and composition of cerebrospinal fluid from the cat choroid plexus. Can J Physiol Pharmacol 1982;60(3):405-9.

29. Smith QR, Johanson CE. Effect of carbonic anhydrase inhibitors and acidosis in choroid plexus epithelial cell sodium and potassium. J Pharmacol Exp Ther 1980;215(3):673-80.

30. Vogh BP et al. Effect of $\mathrm{AlCl}_{3}$ and other acids on cerebrospinal fluid production: a correction. $\mathrm{J}$ Pharmacol Exp Ther 1987;243(1):35-9.

31. Karimy JK et al. A novel method to study cerebrospinal fluid dynamics in rats. J Neurosci Methods 2015;241:78-84.

32. MacAulay N. Molecular mechanisms of brain water transport. Nat Rev Neurosci 2021;22(6).

33. de Rougemont J et al. Fluid Formed by Choroid Plexus: a Technique for its Collection and Comparison of its Electrolyte Composition with Serum and Cisternal Fluids. J. Neurophysiol. $1960 ; 23(5)$.

34. Spector $\mathrm{R}$ et al. A balanced view of choroid plexus structure and function: Focus on adult humans. Exp Neurol. 2015;267:78-86.

35. Damkier HH et al. Cerebrospinal fluid secretion by the choroid plexus. Physiological Reviews 2013;93(4):1847-1892.

36. Praetorius J et al. A SCL4A10 gene product maps selectively to the basolateral plasma membrane of choroid plexus epithelial cells. Am J Physiol Cell Physiol. 2004;286(3).

37. Lindsey AE et al. Functional expression and subcellular localization of an anion exchanger cloned from choroid plexus. Proc Natl Acad Sc USA 1990;87(14).

38. Bouzinova $\mathrm{E}$ et al. $\mathrm{Na}^{+}$-dependent $\mathrm{HCO}_{3}{ }^{-}$uptake into the rat choroid plexus epithelium is partially DIDS sensitive. Am J Physiol Cell Physiol 2005;289(6).

39. Millar ID, Brown PD. NBCe2 exhibits a 3:1 Na+ stoichiometry in mouse choroid plexus epithelial cells. Biochem Biophys Res Commun 2008;373(4). 
40. Jacobs $\mathrm{S}$ et al. Mice with targeted Slc4a10 gene disruption have small brain ventricles and show reduced neuronal excitability. Proc Natl Acad Sci U S A 2008;105(1):311-6.

41. Kao L et al. Severe neurologic impairment in mice with targeted disruption of the electrogenic sodium bicarbonate cotransporter NBCe2 (Slc4a5 Gene). J Biol Chem 2011;286(37):32563-74.

42. Kallio $\mathrm{H}$ et al. Expression of carbonic anhydrases IX and XII during mouse embryonic development. BMC Developmental Biology 2006;6(22).

43. Parkkila S et al. Expression of membrane-associated carbonic anhydrase XIV on neurons and axons in mouse and human brain. Proc Natl Acad Sc USA 2001;98(4):1918-1923.

44. Nógrádi A et al. Localization of acetazolamide-resistant carbonic anhydrase III in human and rat choroid plexus by immunocytochemistry and in situ hybridisation. Neurosci Lett 1993;151(2):162165.

45. Kumpulainen T, Korhonen LK. Immunohistochemical localization of carbonic anhydrase isoenzyme $\mathrm{C}$ in the central and peripheral nervous system of the mouse. J Histochem Cytochem $1982 ; 30(4): 283-292$.

46. Ivanov S et al. Expression of Hypoxia-Inducible Cell-Surface Transmembrane Carbonic Anhydrases in Human Cancer. Am J Pathol 2001;158(3):905-919.

47. Clapp JR et al. Effect of carbonic anhydrase inhibition on proximal tubular bicarbonate reabsorption. Am J Physiol 1963;205:693-6.

48. Wettrell K, Pandolfi M. Propranolol vs Acetazolamide A Long-term Double-Masked Study of the Effect on Intraocular Pressure and Blood Pressure. Arch Ophthalmol 1979;97(2):280-283.

49. Eskandari D et al. Acetazolamide reduces blood pressure and sleep-disordered breathing in patients with hypertension and obstructive sleep apnea: A randomized controlled trial. J Clin Sleep Med 2018;14(3):309-317.

50. Carey M, Vela A. Effect of systemic arterial hypotension on the rate of cerebrospinal fluid formation in dogs. J. Neurosurg 1974;41(3):350-5. 
51. Adamson R, Swenson ER. Acetazolamide use in severe chronic obstructive pulmonary disease pros and cons. Ann Am Thorac Soc 2017;14(7):1086-1093.

52. Cardenas $\mathrm{V}$ et al. Kinetics of $\mathrm{CO}_{2}$ excretion and intravascular $\mathrm{pH}$ disequilibria during carbonic anhydrase inhibition. J Appl Physiol (1985) 1998;84(2):683-94.

53. Taxi K et al. Disturbance of C02 Elimination in the Lungs by Carbonic Anhydrase Inhibition. Jpn J Physiol 1986;36(3):523-32.

54. Zhang Z et al. Hyperventilation in neurological patients: From physiology to outcome evidence. Curr Opin Anaesthesiol. 2019;32(5):568-573.

55. Dahan A, Teppema LJ. Influence of anaesthesia and analgesia on the control of breathing. Br J Anaesth 2003;91(1):40-9.

56. Kilkenny $\mathrm{C}$ et al. research: Reporting in vivo experiments: The ARRIVE guidelines. Br J Pharmacol 2010;160(7):1577-9.

57. Maren TH. Use of inhibitors in physiological studies of carbonic anhydrase. Am J Physiol 1977;232(4):291-7.

58. Keep RF et al. Potassium cotransport at the rat choroid plexus. Am J Physiol Cell Physiol $1994 ; 267(6)$.

59. Dobin A et al. STAR: ultrafast universal RNA-seq aligner. Bioinformatics 2013;29(1).

60. Abrams ZB, Johnson TS, Huang K, Payne PRO, Coombes K. A protocol to evaluate RNA sequencing normalization methods. BMC Bioinform 2019;20(S24).

61. Rodríguez-Lorenzo $\mathrm{S}$ et al. Altered secretory and neuroprotective function of the choroid plexus in progressive multiple sclerosis. Acta Neuropathologica Communications 2020;8(1):35.

62. Lun MP et al. Spatially Heterogeneous Choroid Plexus Transcriptomes Encode Positional Identity and Contribute to Regional CSF Production. Journal of Neuroscience 2015;35(12):4903-4916.

63. Andrews S. FastQC: A Quality Control Tool for High Throughput Sequence Data. http://www.bioinformatics.babraham.ac.uk/projects/fastqc 
64. Bolger AM et al. Trimmomatic: a flexible trimmer for Illumina sequence data. Bioinformatics 2014;30(15):2114-2120.

65. Guild S-J et al. Recording of intracranial pressure in conscious rats via telemetry. J Appl Physiol 2015;119:576-581.

66. Relman A et al. Oral administration of a potent carbonic anhydrase inhibitor (diamox). I. changes in electrolyte and acid-base balance. N Engl J Med 1954;250(18):759-64.

67. Steffensen $A B$ et al. Cotransporter-mediated water transport underlying cerebrospinal fluid formation. Nat Commun 2018;9(1).

68. Oliveira LM et al. Normal-pressure hydrocephalus: A critical review. Dement Neuropsychol 2019;13(2):133-143.

69. Alperin $\mathrm{N}$ et al. Low-dose acetazolamide reverses periventricular white matter hyperintensities in iNPH. Neurology 2014;82(15).

70. Williamson MR et al. Acetazolamide Mitigates Intracranial Pressure Spikes Without Affecting Functional Outcome After Experimental Hemorrhagic Stroke. Transl Stroke Res 2019;10(4):428-439.

71. Guo F et al. Inhibition of Carbonic Anhydrase Reduces Brain Injury After Intracerebral Hemorrhage. Transl Stroke Res 2012;3(1):130-137.

72. Thompson S et al. The effect of acetazolamide on intracranial pressure: primary study with prolonged continuous intracranial pressure monitoring. J Neurol Neurosurg Psychiatry 2019;90(3):e16.1-e16.

73. Faraci FM et al. Effect of vasopressin on production of cerebrospinal fluid: possible role of vasopressin (V1) receptors. Am J Physiol 1990;258:94-8.

74. Battisti-Charbonney A et al. The cerebrovascular response to carbon dioxide in humans. J Physiol 2011;589(12):3039-3048.

75. Dodgson SJ. Inhibition of mitochondrial carbonic anhydrase and ureagenesis: a discrepancy examined. J Appl Physiol (1985) 1987;63(5):2134-41. 
bioRxiv preprint doi: https://doi org/10.1101/2022 01.11.475854; this version posted January 12,2022 . The copyright holder for this preprint (which was not certified by peer review) is the author/funder, who has granted bioRxiv a license to display the preprint in perpetuity. It is made available under aCC-BY-NC-ND 4.0 International license.

Table 1 Comparison of carbonic anhydrase expression levels in the control (administered p.o. saline once daily for 7 days) rat choroid plexus with the RNAseq data available from mice (62) and from humans (61). The isoforms are presented from the highest to the lowest expression in rats. TPM: transcript per million.

\begin{tabular}{|c|c|c|c|c|}
\cline { 3 - 5 } \multicolumn{2}{l|}{} & Rat, & Mouse, & Human, \\
\hline 1 & CA2 & 785 & 368 & 1064 \\
\hline 2 & CA14 & 92 & 243 & 50 \\
\hline 3 & CA4 & 15 & - & 6 \\
\hline 4 & CA12 & 13 & 828 & 107 \\
\hline 5 & CA11 & 10 & 42 & 28 \\
\hline 6 & CA6 & 8 & - & - \\
\hline 7 & CA13 & 7 & 3 & 0.9 \\
\hline 8 & CA9 & 3 & - & - \\
\hline 9 & CA5B & 3 & 4 & 9 \\
\hline 10 & CA3 & 0.6 & 4 & 1 \\
\hline 11 & CA8 & 0.3 & 1 & 3 \\
\hline 12 & CA7 & 0.2 & - & - \\
\hline 13 & CA1 & 0.2 & - & 1 \\
\hline & CA10 & - & 132 & - \\
\hline & CA15 & - & 7 & - \\
\hline
\end{tabular}


bioRxiv preprint doi: $h$ ttps://doi.org/10.1101/2022.01.11.475854; this version posted January 12,2022 . The copyright holder for this preprint (which was not certified by peer review) is the author/funder, who has granted bioRxiv a license to display the preprint in perpetuity. It is made available under aCC-BY-NC-ND 4.0 International license.

Table 2 Expression levels, the fold change ( $\left.\log _{2} \mathrm{FC}\right)$, and the \% change of main transporters, channels and carbonic anhydrases in the rats choroid plexus after treatment with either control solution (CTRL) or $100 \mathrm{mg} \mathrm{ml}^{-1}$ AZE p.o. for 7 days (AZE), in transcripts per million (TPM). Control values for carbonic anhydrases are those from Table 1.

\begin{tabular}{|c|c|c|c|c|c|c|c|}
\hline & Gene & Alias & Description & CTRL & AZE & $\log _{2} \mathrm{FC}$ & $\%$ change \\
\hline \multirow{10}{*}{ 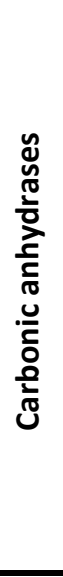 } & CA2 & CAll & Carbonic anhydrase 2 & 785 & 715 & -0.14 & -9 \\
\hline & CA14 & CAXIV & Carbonic anhydrase 14 & 92 & 102 & 0.15 & 11 \\
\hline & CA4 & CAIV & Carbonic anhydrase 4 & 15 & 7.3 & -1.03 & -51 \\
\hline & CA12 & CAXII & Carbonic anhydrase 12 & 13 & 30 & 1.26 & 140 \\
\hline & CA11 & CAXI & Carbonic anhydrase 11 & 10 & 9.1 & -0.10 & -6 \\
\hline & CA6 & CAVI & Carbonic anhydrase 6 & 8.4 & 6.7 & -0.33 & -21 \\
\hline & CA13 & CAXIII & Carbonic anhydrase 13 & 7.2 & 10 & 0.48 & 40 \\
\hline & CA9 & CAIX & Carbonic anhydrase 9 & 2.9 & 4.4 & 0.60 & 51 \\
\hline & CA5B & CAVB & Carbonic anhydrase 5B & 2.8 & 2.3 & -0.27 & -17 \\
\hline & CA3 & CAIII & Carbonic anhydrase 3 & 0.6 & 0.7 & 0.17 & 12 \\
\hline \multirow{4}{*}{ 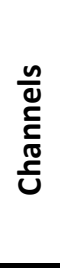 } & KCNJ13 & Kir7.1 & Inwardly rectifying $\mathrm{K}^{+}$channel 7.1 & 192 & 237 & 0.31 & 24 \\
\hline & AQP1 & AQP1 & Aquaporin 1 & 161 & 197 & 0.30 & 23 \\
\hline & TRPV4 & TRPV4 & $\begin{array}{l}\text { Transient receptor potential } \\
\text { vanilloid channel } 4 \\
\end{array}$ & 34 & 38 & 0.18 & 13 \\
\hline & CLCN6 & $\mathrm{ClC}-6$ & Voltage-gated $\mathrm{Cl}^{-}$channel 6 & 3.9 & 4.4 & 0.18 & 13 \\
\hline \multirow{13}{*}{ 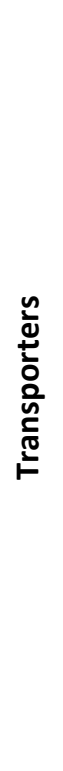 } & FXYD1 & FXYD1 & $\mathrm{Na}^{+} / \mathrm{K}^{+}$-ATPase $\gamma 1$ & 1449 & 1861 & 0.36 & 28 \\
\hline & ATP1B1 & NKA.b1 & $\mathrm{Na}^{+} / \mathrm{K}^{+}$-ATPase $\beta 1$ & 365 & 370 & 0.02 & 1 \\
\hline & ATP1B2 & NKA.b2 & $\mathrm{Na}^{+} / \mathrm{K}^{+}$-ATPase $\beta 2$ & 158 & 132 & -0.26 & -16 \\
\hline & SLC12A2 & NKCC1 & $\mathrm{Na}^{+}, \mathrm{K}^{+}, 2 \mathrm{Cl}^{-}$cotransporter & 96 & 93 & -0.04 & -3 \\
\hline & ATP1A1 & NKA.a1 & $\mathrm{Na}^{+} / \mathrm{K}^{+}$-ATPase $\alpha 1$ & 82 & 117 & 0.52 & 44 \\
\hline & SLC4A2 & AE2 & $\mathrm{Cl}^{-}, \mathrm{HCO}_{3}^{-}$exchanger & 77 & 106 & 0.46 & 38 \\
\hline & SLC4A10 & NCBE & $\mathrm{Na}^{+}, \mathrm{HCO}_{3}^{-}$cotransporter & 54 & 56 & 0.04 & 3 \\
\hline & SLC12A4 & KCC1 & $\mathrm{K}^{+}, \mathrm{Cl}^{-}$cotransporter & 40 & 49 & 0.28 & 21 \\
\hline & SLC12A7 & KCC4 & $\mathrm{K}^{+}, \mathrm{Cl}^{-}$cotransporter 4 & 40 & 35 & -0.19 & -12 \\
\hline & SLC4A5 & NBCE2 & $\mathrm{Na}^{+}, \mathrm{HCO}_{3}{ }^{-}$cotransporter & 38 & 68 & 0.85 & 80 \\
\hline & SLC9A6 & NHE6 & $\mathrm{Na}^{+}, \mathrm{H}^{+}$exchanger 6 & 6.8 & 7.3 & 0.12 & 9 \\
\hline & SLC9A1 & NHE1 & $\mathrm{Na}^{+}, \mathrm{H}^{+}$exchanger 1 & 3.7 & 3.0 & -0.31 & -20 \\
\hline & SLC12A6 & KCC3 & $\mathrm{K}^{+}, \mathrm{Cl}^{-}$cotransporter 3 & 3.1 & 2.3 & -0.45 & -27 \\
\hline
\end{tabular}



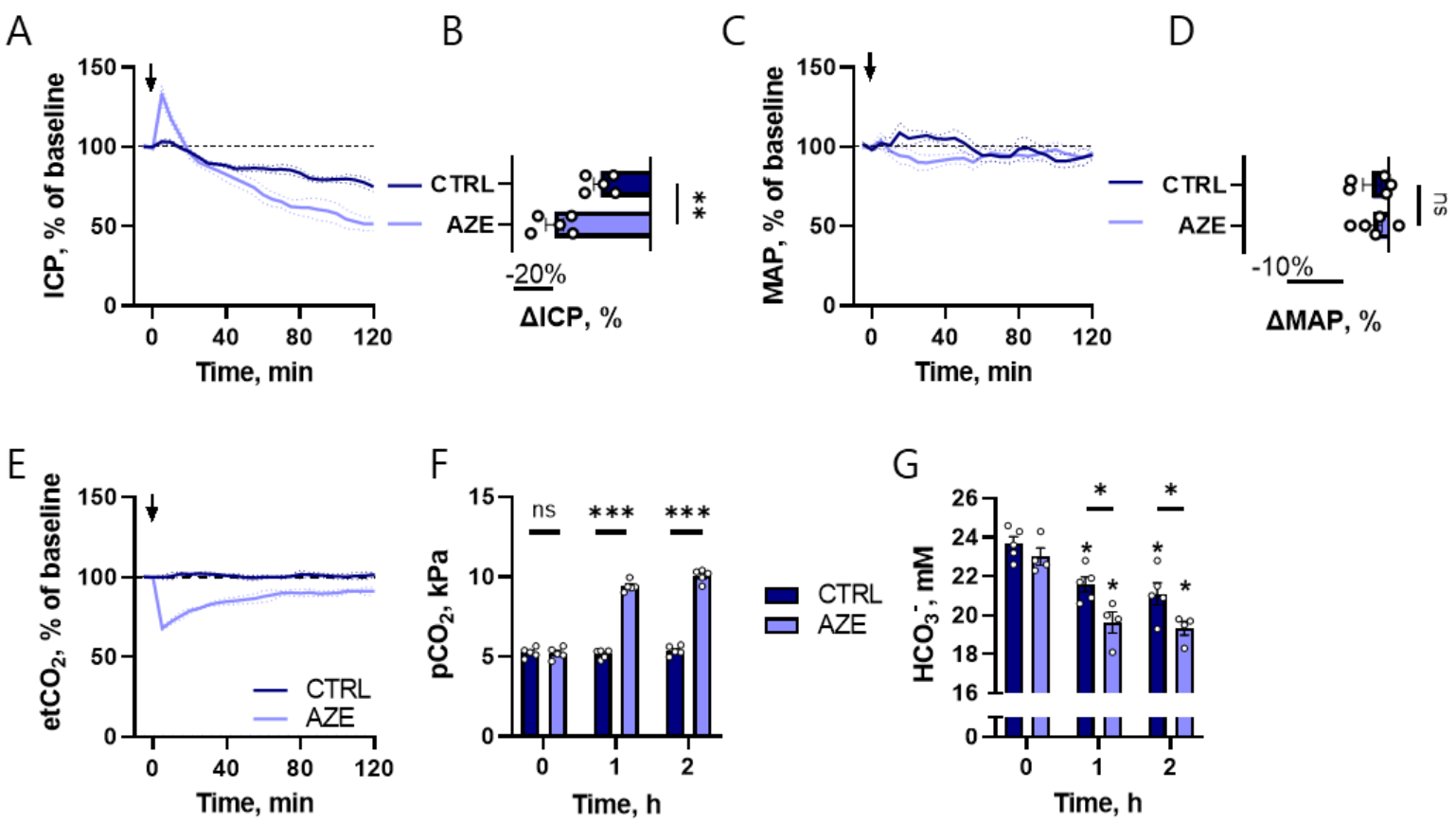

Figure 1 Effect of i.v. administration of $100 \mathrm{mg} \mathrm{kg}^{-1}$ AZE in anesthetized and ventilated rats. The ICP

(A), MAP (C) and etCO $(\mathrm{E})$ is presented as $5 \mathrm{~min}$ average values normalized to the baseline $(10 \mathrm{~min}$ average value obtained before control solution or AZE administration) as a function of time. The change from baseline at $2 \mathrm{~h}$ after the injection is shown for ICP (B) and MAP (D). Blood gas analysis was performed before $(0 \mathrm{~h})$ and 1 and $2 \mathrm{~h}$ after the injection, and results are presented for $\mathrm{pCO}_{2}(\mathbf{F})$ and for blood $\mathrm{HCO}_{3}^{-}$, asterisks indicate significance for time variable, whereas bars indicate significance for treatment (G). Arrow indicates time of i.v. injection. 
A

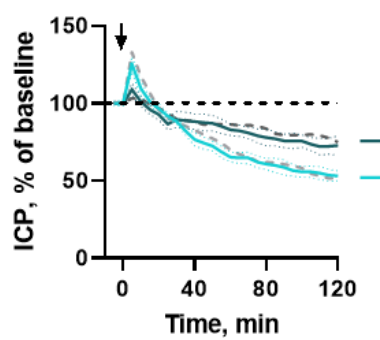

E

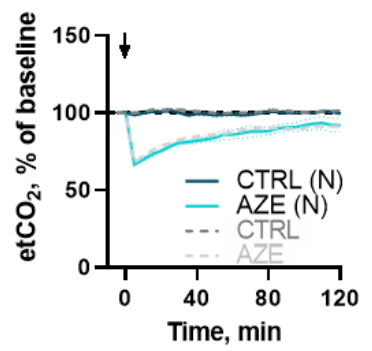

B

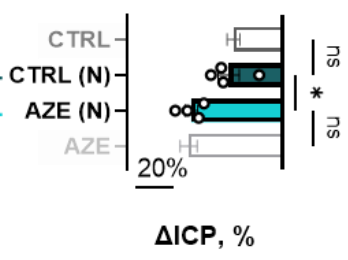

$\mathrm{F}$

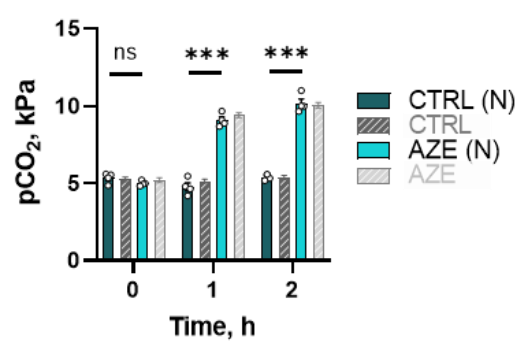

C
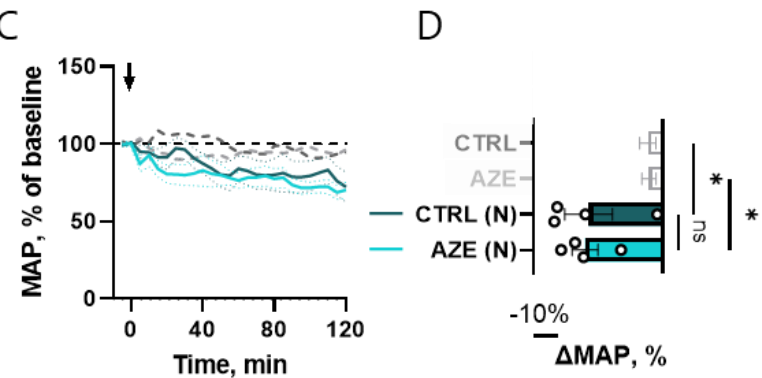

G

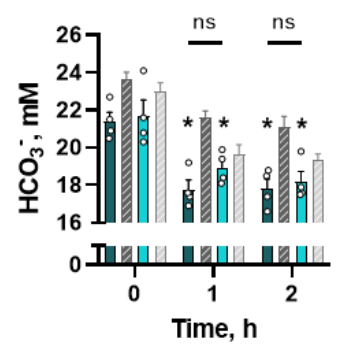

Figure 2 Effect of i.v. administration of $100 \mathrm{mg} \mathrm{kg}^{-1}$ AZE in anesthetized, ventilated and nephrectomized rats. ICP (A), MAP (C) and et $\mathrm{CO}_{2}(\mathrm{E})$ is presented in the same manner as Figure 1 , as well as change at the $2 \mathrm{~h}$ after the injection for ICP (B) and MAP (D). Results from the blood gas analysis are presented for $\mathrm{pCO}_{2}(\mathbf{F})$ and blood $\mathrm{HCO}_{3}{ }^{-}$, asterisks indicate significance for time variable, whereas bars indicate significance for treatment (G). Dark grey and light grey results are obtained from Figure 1. Arrow indicates time of i.v. injection. $(\mathrm{N})=$ nephrectomized rats. 

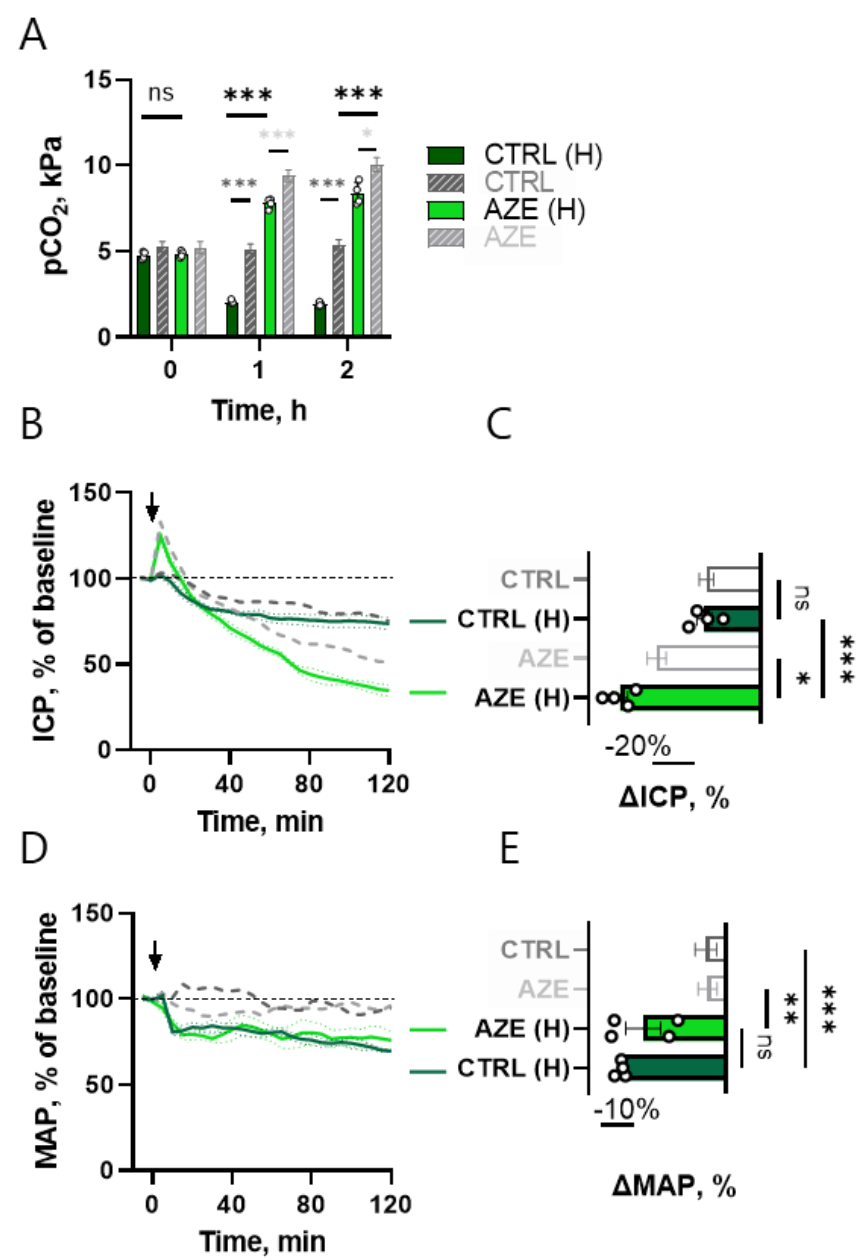

Figure 3 Effect of i.v. injection of $100 \mathrm{mg} \mathrm{kg}^{-1}$ AZE in anesthetized and hyperventilated rats. Hyperventilation was induced by increasing the tidal volume and the respiratory rate by $50 \%$ from the baseline value over $5 \mathrm{~min}$ after the injection of treatment, which caused $\mathrm{pCO}_{2}$ reduction $(\mathbf{A})$. The ICP (B) and MAP (D) are presented as function of time in the same manner as in Figure 1, with end $2 \mathrm{~h}$ change shown in C (ICP) and E (MAP). Dark grey and light grey results are obtained from Figure 1. Arrow indicates time of i.v. injection. $(\mathrm{H})=$ hyperventilated rats. 
A
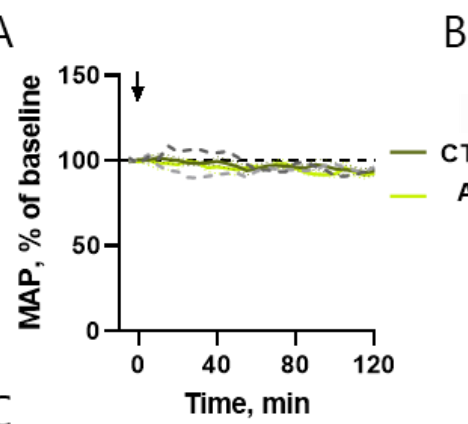

B
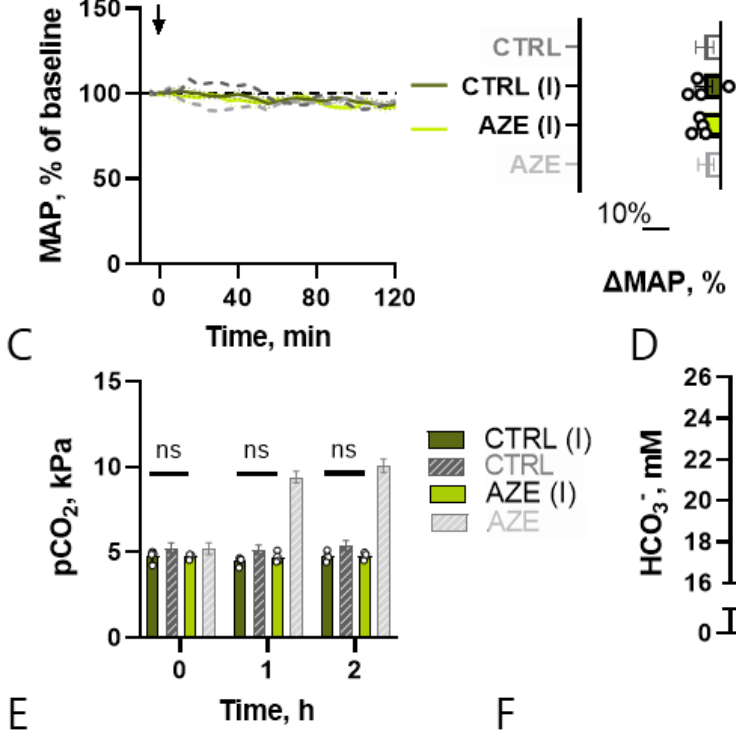

$\triangle M A P, \%$

D
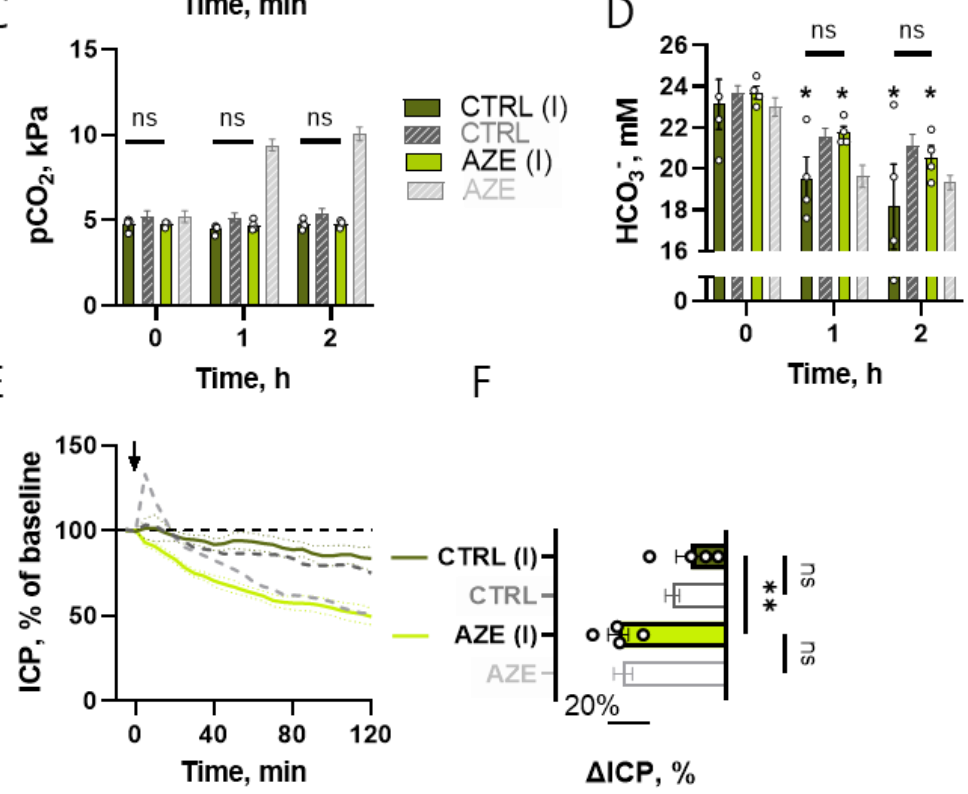

Figure 4 Effect of i.c.v. infusion of either control solution or $18 \mathrm{mM}$ (expected ventricular concentration of $\max 500 \mu \mathrm{M})$ AZE at a rate of $0.5 \mu \mathrm{min}^{-1}$ in anesthetized and ventilated rats. MAP

(A) is presented in the same manner as Figure 1 , with $2 \mathrm{~h}$ end MAP shown at $\mathbf{B}\left(\triangle \mathrm{MAP}_{\mathrm{CTRL}(\mathrm{I})}=-6 \pm 3 \%\right.$, $\triangle \mathrm{MAP}_{\mathrm{AZE}(\mathrm{I})}=-7 \pm 1 \%, \mathrm{P}=0.9$ ), as well as blood $\mathrm{pCO}_{2}(\mathrm{C})$ and blood $\mathrm{HCO}_{3}{ }^{-}$, asterisks indicate significance for time variable, whereas bars indicate significance for treatment (D). Effect of AZE i.c.v. as a function of time is shown in $\mathbf{E}$, with end $2 \mathrm{~h}$ change at $\mathbf{F}$. Dark grey and light grey results are obtained from Figure 1. Arrow indicates the start of i.c.v. infusion. $(I)=$ rats receiving i.c.v. delivery of AZE. 

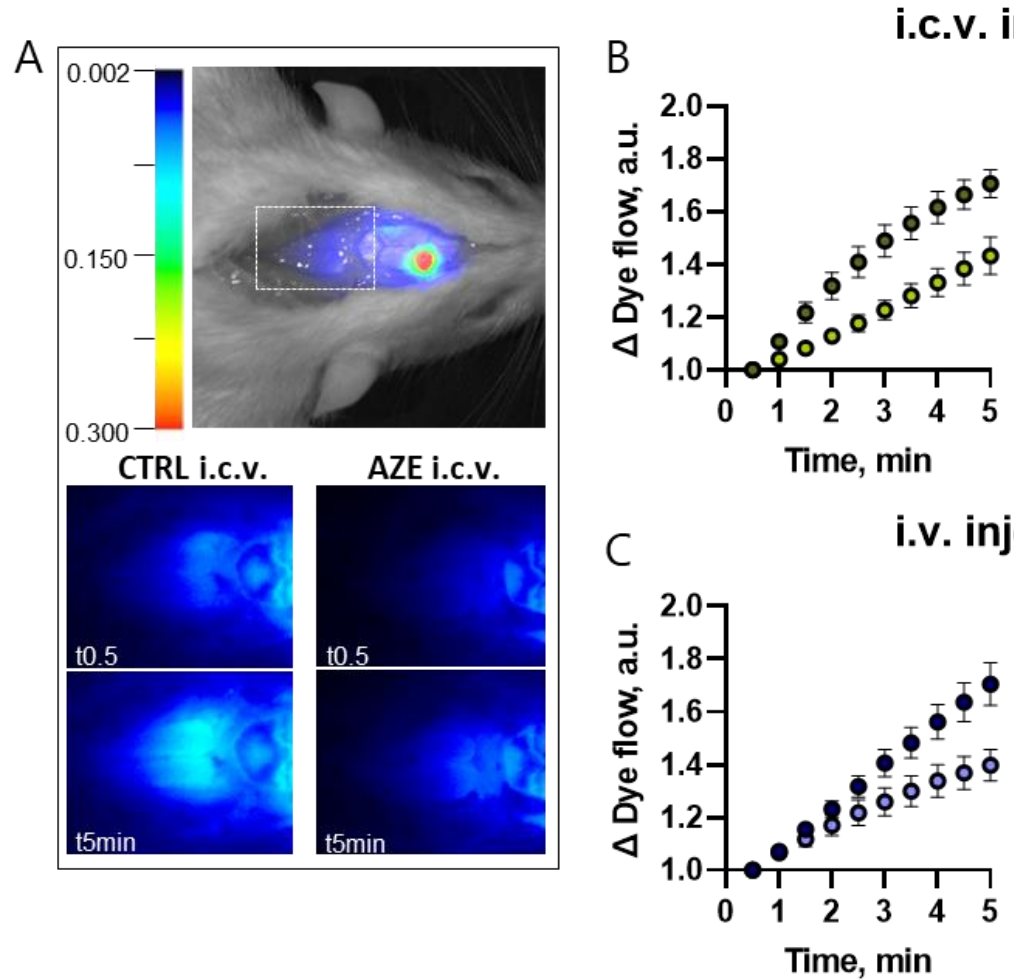

i.c.v. injection
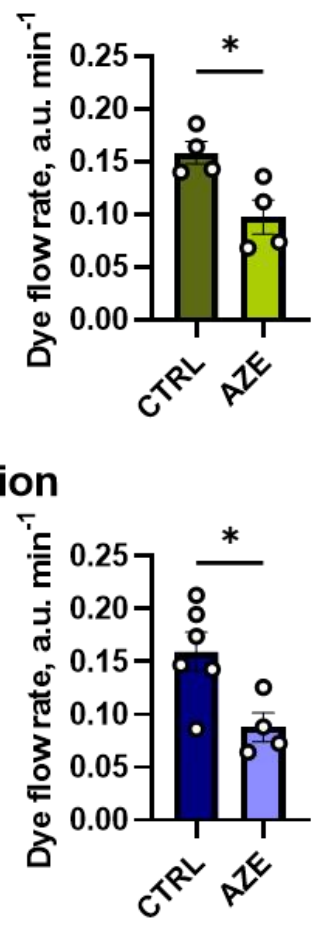

Figure 5 Live imaging of fluorescent dye as a proxy of CSF secretion following treatment with AZE.

The top panel in A illustrates pseudo-color fluorescence superimposed on a white light image from a rat after ventricular injection of IRDye $800 \mathrm{CW}$ carboxylate dye. The white box below lambda illustrates the area for dye intensity quantification. The bottom panel illustrates representative images of fluorescence signal 0.5 and $5 \mathrm{~min}$ after i.c.v. injection of control solution or $2 \mathrm{mM}$ AZE solutions (expected ventricular concentration $200 \mu \mathrm{M}$ ). Quantification of the dye flow normalized to the first image after i.c.v. injection is shown in panel B. Panel C shows the quantification of the dye flow normalized to the first image after i.v. injection of control solution or $100 \mathrm{mg} \mathrm{kg}^{-1} \mathrm{AZE}$. 

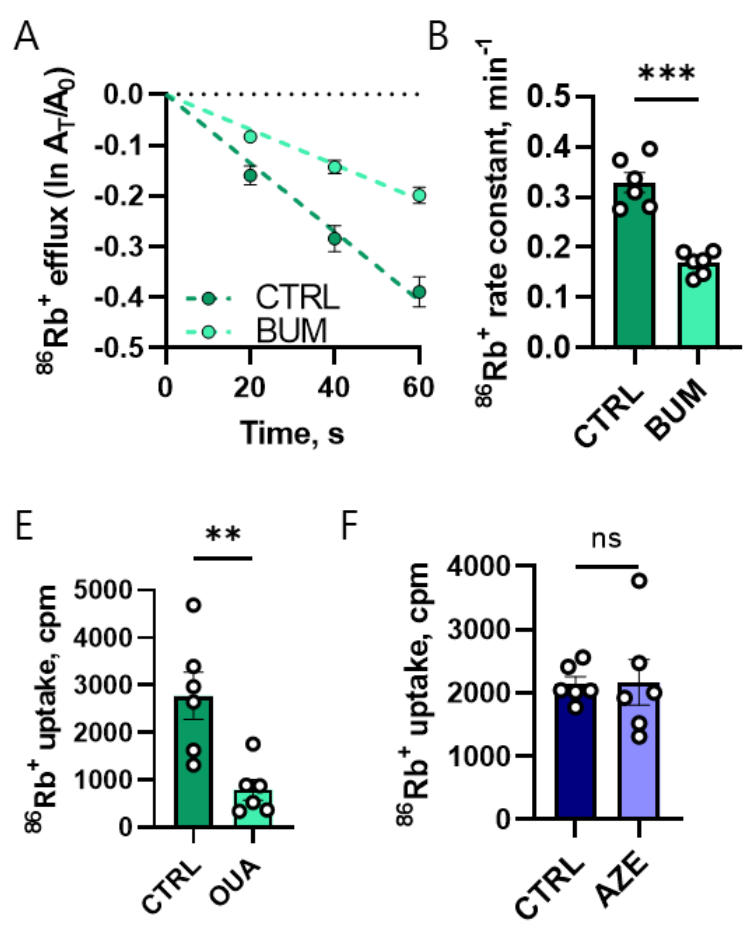
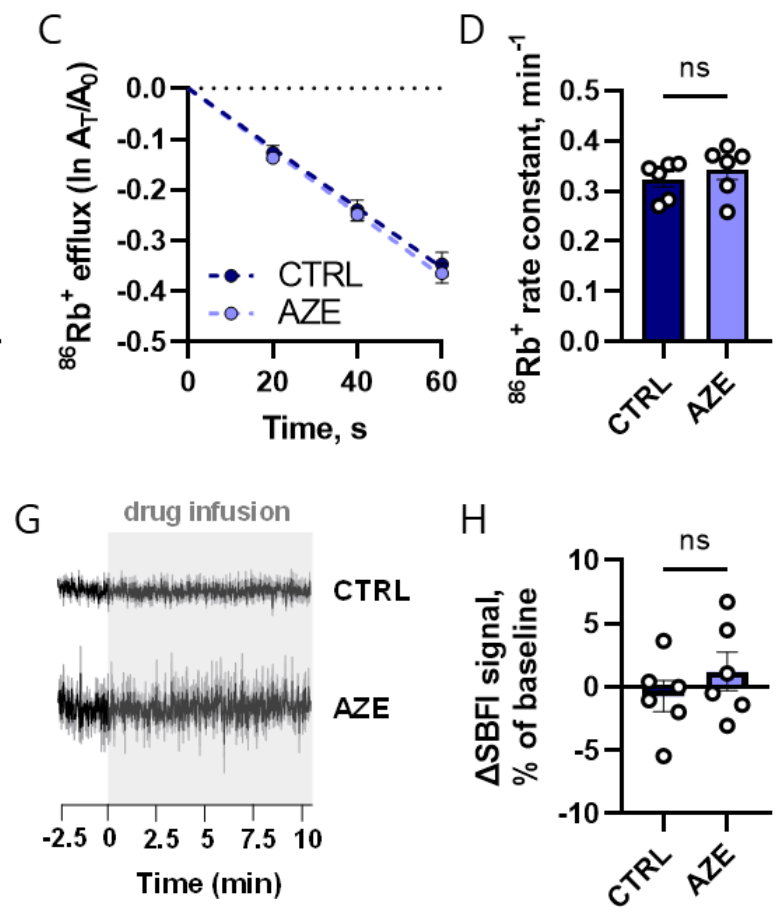

Figure 6 AZE's effect on the activity of selected key CSF secreting transporters. ${ }^{86} \mathrm{Rb}^{+}$efflux rate (a read out for NKCC1 activity) is presented as a function of time upon treatment with either $20 \mu \mathrm{M}$ bumetanide (A) or $200 \mu \mathrm{M}$ AZE (C). The efflux rate constant was quantified using linear regression analysis for bumetanide (B) and AZE (D). ${ }^{86} \mathrm{Rb}^{+}$uptake rate (read out for $\mathrm{Na}^{+} / \mathrm{K}^{+}$-ATPase activity) is shown after treatment with $2 \mathrm{mM}$ ouabain (E) and after treatment with $200 \mu \mathrm{M}$ AZE (F). $\mathrm{Na}^{+}{ }_{\mathrm{i}}$ sensitive SBFI dye traces during exposure to $200 \mu \mathrm{M}$ AZE or control solution are shown in $\mathbf{G}$, and quantified in H (CTRL: $-0.7 \pm 1.2 \%$, AZE: $1.2 \pm 1.5 \%, n=6, P=0.34)$. 

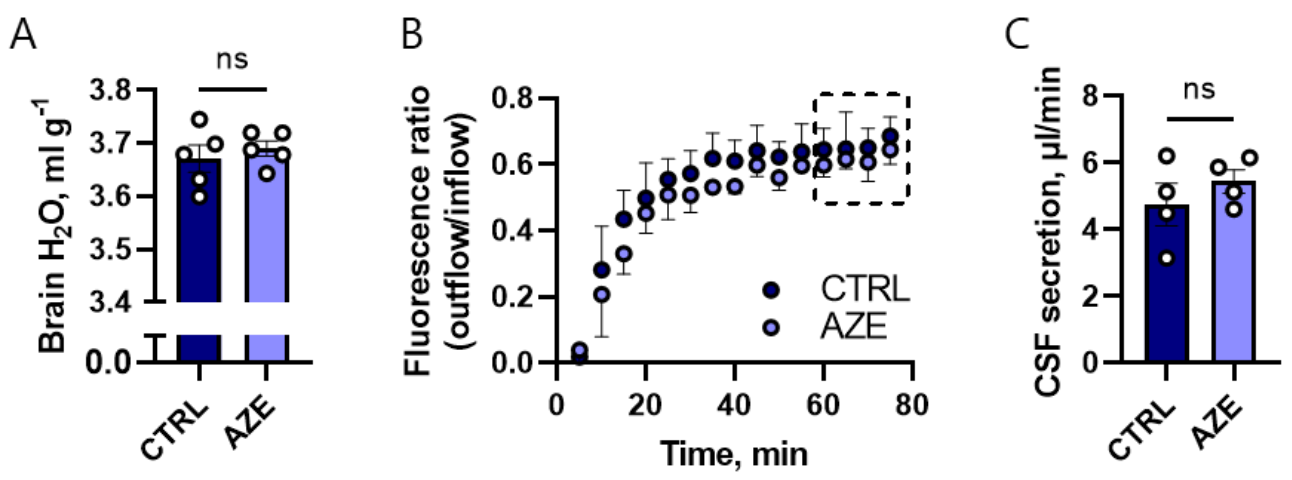

Figure 7 Effect of $1 \times$ daily administration of $100 \mathrm{mg} \mathrm{kg}^{-1}$ p.o. AZE or control solution on brain water content and CSF secretion rate, measured $24 \mathrm{~h}$ after the last dose. Panel A represents the brain water content expressed as $\mathrm{ml} \mathrm{g}^{-1}$ dry weight. Figure B shows the average dextran dye dilution for control and AZE groups as a function of time. The dashed boxed indicates the period from which the CSF secretion rate was calculated, and the average value for this $20 \mathrm{~min}$ period is presented in $\mathbf{C}$. 


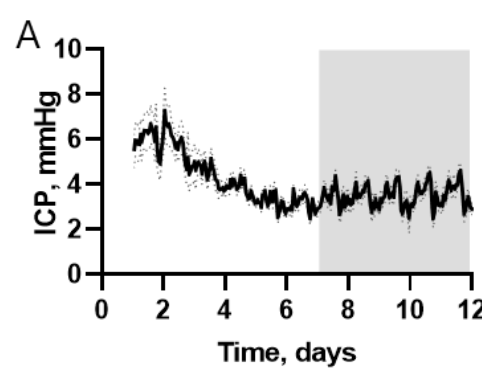

D

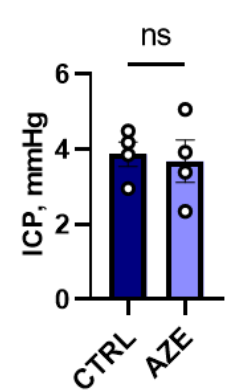

G
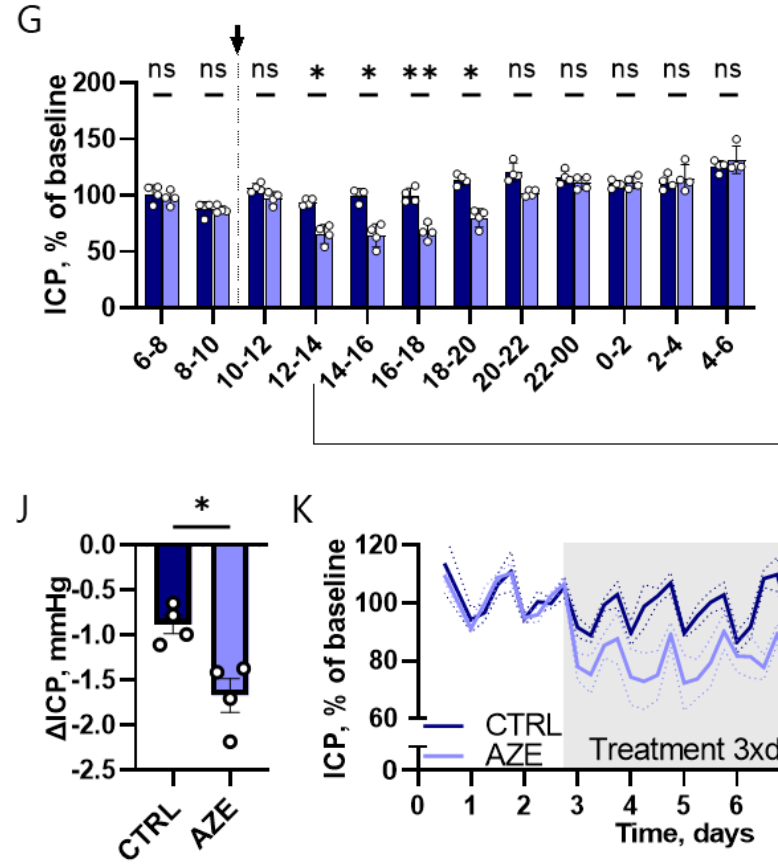

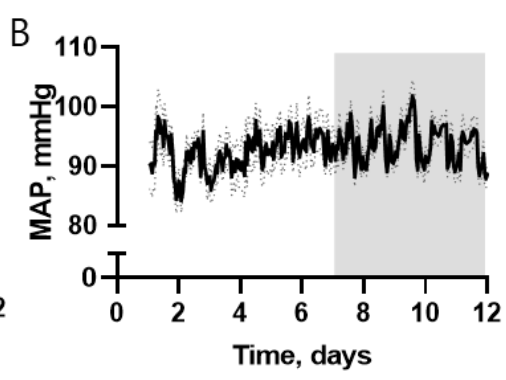

E

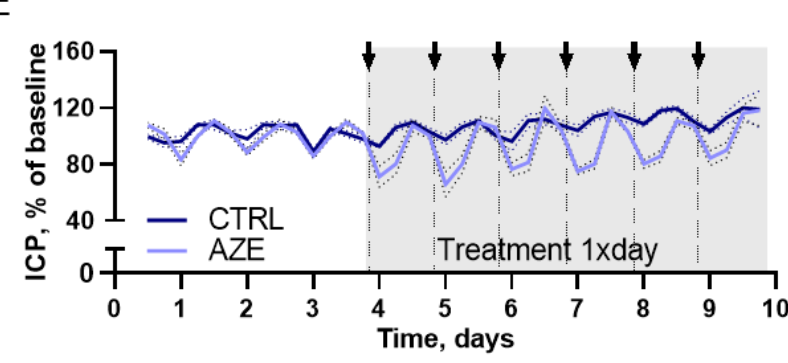

$\mathrm{H}$

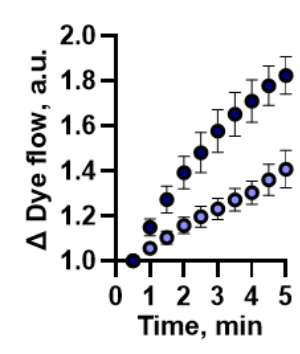

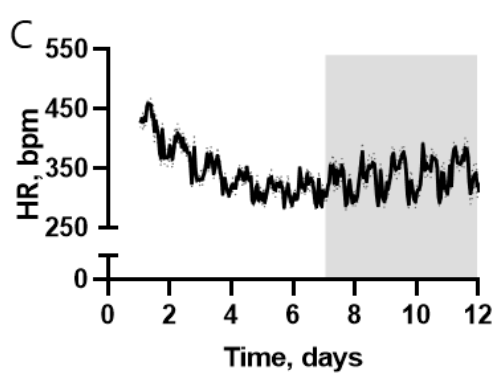

F

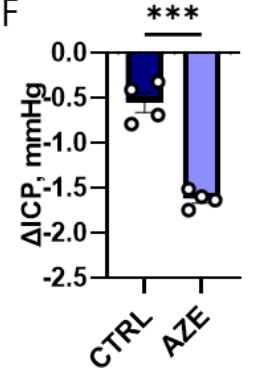

I

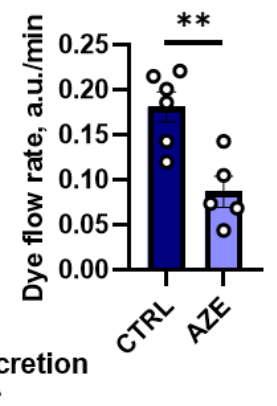

M

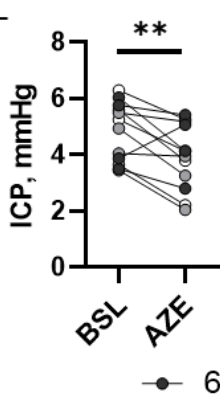

Figure 8 Telemetric measurements of ICP in freely moving awake rats before and during p.o treatment with $100 \mathrm{mg} \mathrm{kg}^{-1}$ AZE. Top panels represent the recovery period after implantation of telemetric device and show daily fluctuations in ICP (A), MAP (B) and heart rate (C). Panel D shows the average ICP over 3 days $(72 \mathrm{~h})$ before initiation of treatment $\left(I C P_{\text {CTRL }}=3.9 \pm 0.3 \mathrm{mmHg}, I_{\text {AZE }}=3.7 \pm\right.$ $0.6 \mathrm{mmHg}, \mathrm{n}=4$ in each, $\mathrm{P}=0.8$ ). The $\%$ change in ICP, normalized to the average $24 \mathrm{~h}$ ICP (baseline) before treatment initiation, is shown in $\mathrm{E}$ for $1 \times$ daily p.o. delivery of $100 \mathrm{mg} \mathrm{kg}^{-1} \mathrm{AZE}$ or control 
solution. The difference between the lowest $1 \mathrm{~h}$ average ICP value (within the first $7 \mathrm{~h}$ after AZE or control solution injection) and the baseline ICP is shown in F. The ICP fluctuations over the $24 \mathrm{~h}$ period after drug administration are represented in $\mathbf{G}$, where an average ICP for each $2 \mathrm{~h}$ period was calculated for controls and AZE treated rats across the six treatment days. 2-3h after p.o. drug administration an IRDye $800 \mathrm{CW}$ carboxylate dye was injected intraventricularly, and the dye flow (H) and rate (I) was used as a proxy to assess the CSF secretion rate. The maximum effect of the $3 \times$ day treatment with $100 \mathrm{mg} \mathrm{kg}^{-1}$ AZE or control solution for 5 days is shown in panel J. The $\triangle I C P$ was calculated as difference between the baseline ICP and minimum $1 \mathrm{~h}$ average ICP during the $7 \mathrm{~h}$ after each (of 14) AZE or control solution p.o. delivery. In K, ICP fluctuations during the $3 \times$ day treatment, normalized to baseline ICP are shown. The average ICP at 6, 13 and 20 o'clock (the hour before p.o. treatment administration) was calculated for the baseline period, and compared to average ICP at the same time points during $3 \times$ day treatment with $100 \mathrm{mg} \mathrm{kg}^{-1}$ AZE (L) or control solution (M). 


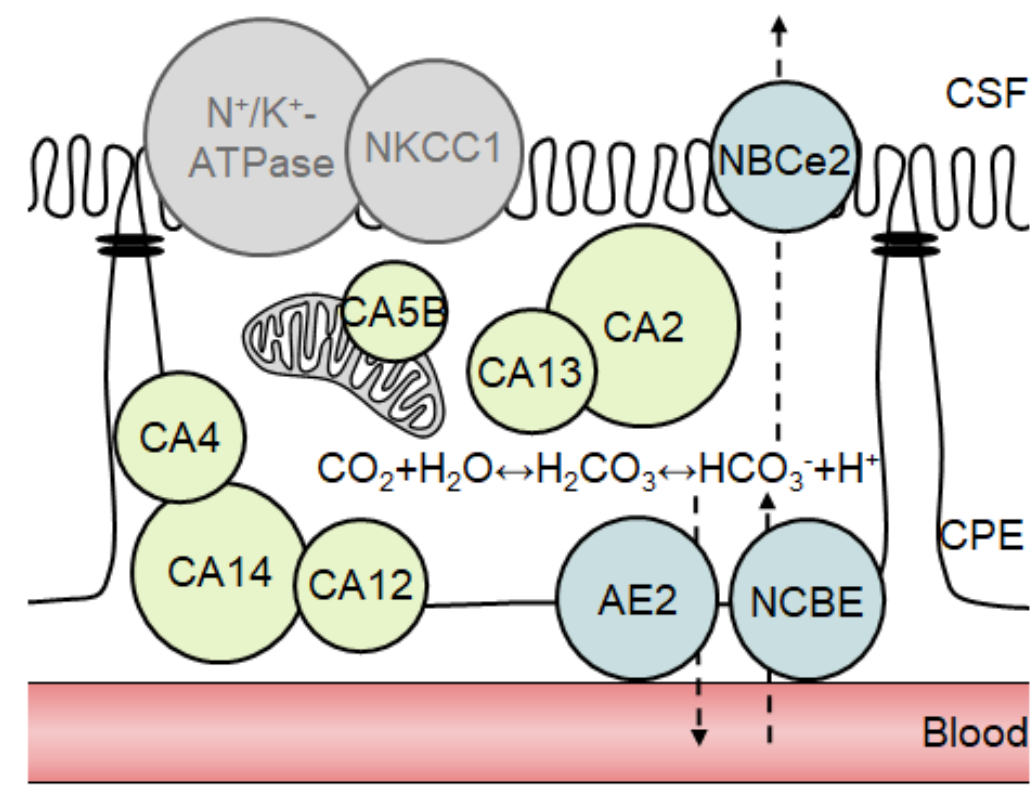

Figure 9 Schematic representation of carbonic anhydrases and transporters in a choroid plexus

epithelial (CPE) cell. CA12 is expressed on the basolateral side of the choroid plexus (42), CA4, CA9 and CA14 are generally membrane bound (4), yet their exact localization (luminal or basolateral) in the choroid plexus cell remains unresolved. CA2 and CA13 are both cytosolic $(4,45)$, whereas CA5B is found in mitochondria (75). Not shown are CA6 and CA9, which are absent from mouse and human choroid plexus (Table 1), CA3, which is AZE insensitive (44), and CA11, which may be acatalytic (4). CA isoforms $1,7,8,10$ and 15 were bellow detection level in rat choroid plexus (Table 1). The key transporters involved in CSF secretion NKCC1 and Na/K-ATPase are not affected by AZE treatment. The main candidates for mediating AZE-induced reduction in CSF secretion are the bicarbonate transporters: AE2 and NBCE/NBCn2 expressed at the basolateral membrane and NBCe2 expressed at the luminal membrane. The sphere area indicates transcriptional expression levels. 